Linköping Studies in Science and Technology

Dissertations No. 1681

\title{
High Temperature Fatigue Crack Growth in a Ni-based Superalloy \\ Modelling Including the Interaction of Dwell Times
}

Erik Storgärds

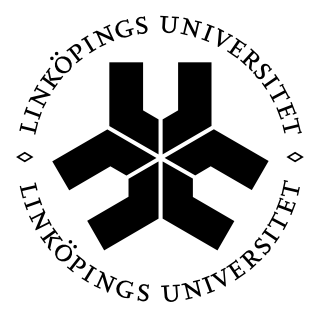

Linköping University

Division of Solid Mechanics

Department of Management and Engineering

Linköping University

SE-581 83 Linköping, Sweden

Linköping, July 2015 
Printed by:

LiU-Tryck, Linköping, Sweden, 2015

ISBN: 978-91-7519-034-1

ISSN: 0345-7524

Distributed by:

Linköping University

Department of Management and Engineering

SE-581 83 Linköping, Sweden

\section{2015 Erik Storgärds}

This document was prepared with $\mathrm{LT}_{\mathrm{E} X}$, July 28, 2015

No part of this publication may be reproduced, stored in a retrieval system, or be transmitted, in any form or by any means, electronic, mechanical, photocopying, recording, or otherwise, without prior permission of the author. 


\section{Preface}

The work presented in this dissertation has been carried out at the Division of Solid Mechanics, Linköping University within the project High temperature fatigue crack propagation in nickel-based superalloys, which is a part of the research programme TURBO POWER. The programme is a joint collaboration between the Swedish Energy Agency, Siemens Industrial Turbomachinery AB and GKN Aerospace Engine Systems, from which support and founding are gratefully acknowledged.

First, I would like to thank my supervisor Prof. Kjell Simonsson for all his support and guidance. I would also like to thank my assistant supervisors Prof. Johan Moverare ${ }^{1}$, Dr. Tomas Månsson ${ }^{2}$ and Dr. David Gustafsson ${ }^{3}$. I would like to give a special thanks to Prof. Sören Sjöström ${ }^{4}$ for all valuable discussions and support during my time as a Ph.D. student, and M.Sc. Jonas Saarimäki ${ }^{1}$ for working with me in the TURBO POWER programme.

My present and former colleagues at the Division of Solid Mechanics are also gratefully acknowledged for all their help. I would like to thank and acknowledge Mr. Patrik Härnman and Mr. Bo Skoog for all their help and expertise with the mechanical testing at Linköping University. The project teams at Linköping University, GKN Aerospace Engine Systems and Siemens Industrial Turbomachinery $\mathrm{AB}$ are also acknowledged for valuable discussions, a special thanks to Dr. Thomas Hansson ${ }^{2}$ for his support with the mechanical testing and evaluation, Lic. Eng. Per Almroth ${ }^{3}$, Lic. Eng. Björn Sjödin ${ }^{3}$, Prof. Sten Johansson ${ }^{1}$ and Dr. Magnus Hörnqvist ${ }^{2}$ for valuable discussions.

Finally, I would like to thank my beloved wife Andrea for always motivating, encouraging and being there for me, and also my family and friends for all their support.

Erik Storgärds

Linköping, July 2015

\footnotetext{
${ }^{1}$ Division of Engineering Materials, Linköping University

${ }^{2}$ GKN Aerospace Engine Systems

${ }^{3}$ Siemens Industrial Turbomachinery $\mathrm{AB}$

${ }^{4}$ Division of Solid Mechanics, Linköping University
} 



\section{Abstract}

Safe life of gas turbines is always of major concern for manufacturers in order to ensure passenger safety and stable continuous power output. An increasing amount of resources have been put into research and development to assure that all safety aspects are covered in the design of new turbines and to ensure that enough frequent service intervals are scheduled to avoid complications. Many of these issues require good knowledge of material properties and of how to use these in the design process. Some of these relate to fatigue which is of major concern in all parts of a development programme. However, while some fatigue problems have been extensively studied, some have not. One example is crack growth with influence of dwell times at elevated temperature in combination with cyclic loading. Such loading conditions have been shown to give a different cracking behaviour compared to rapid cyclic loading, increasing the growth rate significantly with respect to the number of load cycles. Improved models for predicting this behaviour is therefore of major interest for gas turbine manufacturers, and could substantially increase the reliability. As a result, more research is needed in order solve these problems.

The work presented in this dissertation has focused on how to predict life under the above-mentioned circumstances. The materials used in high temperature gas turbine applications are often nickel-based superalloys, and in this work the most common one, Inconel 718, has been studied. Mechanical experiments have been performed under operation like conditions in order to receive material data for the subsequent modelling work. The modelling approach was chosen such that the underlying physics of the dwell time cracking have been incorporated on a phenomenological basis, creating a model which can be physically motivated as well as used for industrial applications. The main feature of the modelling work has been to track material damage which is received from dwell times, how this interacts with cyclic loading and how it affects the crack growth rate, thus creating a load history dependent model.

The outcome of this work has resulted in a model which is both easy to use and which has shown to give good correlation to available experimental data. Key components such as calibration for cheap and easy parameter determination, validation on complex engine spectra loadings, three dimensional crack growth, overload influences, material scatter, thermo-mechanical fatigue crack growth and the impact of high cycle fatigue loadings, are all covered in the presented work, both as experimental findings and as continuous development of the modelling concept.

The dissertation consists of two parts. In the first an introduction with the theory and background to crack growth with dwell times is given, while the second part consists of 10 papers. 



\section{Populärvetenskaplig sammanfattning}

Utvecklingen av gasturbiner är hela tiden driven av att säkerhet inte får kompromissas med, oavsett om det handlar om stationära turbiner eller flygmotorer. Stora resurser avdelas därför för att hantera sådana aspekter av olika slag, både i nytillverkning och för att säkerställa att service utförs inom rimliga intervall för att en olycka inte ska inträffa. Kännedom om materialen i turbinen, deras egenskaper och hur de ska användas i en designprocess för prediktering av beteendet under lastfall av olika slag är därför av högsta intresse. Ett område som kräver just detta är utmattning av materialen som gör att sprickor kan uppkomma. Dessa sprickor, eller sådana som redan existerar i strukturen från tillverkningstadiet, kan under vissa förhållanden växa till en viss kritisk längd då strukturen går sönder. Utmattning är ett stort område där vissa lastförhållanden har undersökts mer än andra, för vilka robusta modeller tagits fram som används $\mathrm{i}$ industrin idag. Områden som inte har studerats lika frekvent är exempelvis utmattning under konstant last med interaktion av cykliska laster, speciellt under hög temperaturer, vilket också är det som denna avhandling behandlar.

Gasturbinmaterialen som används under hög temperatur är ofta olika varianter av nickelbaserade superlegeringar, och här har Inconel 718 studerats, vilken är en av de vanligaste legeringarna som används idag. Experiment under verklighetsnära förhållanden har genomförts för att studera hur sprickor växer, och senare har dessa resultat använts för utveckling av en sprickväxtlag. Målet att kunna använda den framtagna modellen $i$ ett industrisammanhang har hela tiden varit $i$ fokus, samtidigt som den ska vara fysikaliskt motiverad. Hur materialet skadas har tagits omhand genom en lasthistorieberoende modell i vilken fysikaliskt motiverade parametrar använts som grund. Modellen som utvecklats har visat god korrelation till experiment och även visat på utvecklingsmöjligheter för framtida behov.

Avhandlingen är uppdelad i två delar, där den första delen innehåller en bakgrund till ämnet, medan del två består tio vetenskapliga artiklar. 



\section{List of papers}

In this dissertation, the following papers have been included:

I. D. Gustafsson, E. Lundström ${ }^{1}$ (2013). High temperature fatigue crack growth behaviour of Inconel 718 under hold time and overload conditions, International Journal of Fatigue, Volume 48, pp. 178-186.

II. D. Gustafsson, E. Lundström, K. Simonsson (2013). Modelling of high temperature fatigue crack growth in Inconel 718 under hold time conditions, International Journal of Fatigue, Volume 52, pp. 124-130.

III. E. Lundström, K. Simonsson, D. Gustafsson, T. Månsson (2014). A load history dependent model for fatigue crack propagation in Inconel 718 under bold time conditions, Engineering Fracture Mechanics, Volume 118, pp. 17-30.

IV. E. Lundström, K. Simonsson, T. Månsson, D. Gustafsson (2014). Modelling of fatigue crack growth in Inconel 718 under hold time conditions - application to a flight spectrum, Advanced Materials Research, Volumes 891-892, pp. 759-764.

V. E. Storgärds, K. Simonsson (2015). Crack length evaluation for cyclic and sustained loading at high temperature using potential drop, Experimental Mechanics, Volume 55, Issue 3, pp. 559-568.

VI. E. Storgärds, K. Simonsson, S. Sjöström (2015). Three-dimensional crack growth modelling of a Ni-based superalloy at elevated temperature and sustained loading, Submitted.

VII. E. Storgärds, K. Simonsson, S. Sjöström, D. Gustafsson, T. Månsson (2015). Modelling of crack growth with dwell time for aero engine spectra loadings in a Ni-based superalloy, Proceedings of ASME Turbo Expo 2015, GT2015-42701. Journal of Engineering for Gas Turbines and Power, DOI: 10.1115/1.4031155.

VIII. E. Storgärds, J. Saarimäki, K. Simonsson, S. Sjöström, D. Gustafsson, T. Månsson, J. Moverare (2015). Scatter in dwell time cracking for a Ni-based superalloy in combination with overloads, Proceedings of ASME Turbo Expo 2015, GT2015-42709. Journal of Engineering for Gas Turbines and Power, DOI: 10.1115/1.4031157.

IX. E. Storgärds, K. Simonsson, S. Sjöström, J. Moverare (2015). Thermo-mechanical fatigue crack growth modelling in a Ni-based superalloy subjected to sustained load, Proceedings of ASME Turbo Expo 2015, GT2015-42820. Journal of Engineering for Gas Turbines and Power, DOI: 10.1115/1.4031158.

\footnotetext{
${ }^{1}$ Surname changed from Lundström to Storgärds in March 2014
} 
X. E. Storgärds, J. Saarimäki, K. Simonsson, S. Sjöström, T. Månsson, J. Moverare (2015). Impact of high cycle fatigue on dwell time crack growth in a Ni-based superalloy, To be submitted.

\section{Note}

The appended papers have been reformatted to fit the layout of the dissertation.

\section{Own contribution}

The mechanical experiments have been a joint effort between me, M.Sc. Jonas Saarimäki, Mr. Patrik Härnman and Mr. Bo Skoog, except for Paper IV where it was partly performed at GKN Aerospace in Trollhättan and Paper IX where Prof. Johan Moverare did the TMF testing. All evaluations with potential drop (PD) has been done by me. Scanning Electron Microscopy (SEM) work has been done by M.Sc. Jonas Saarimäki, Lic. Eng. Mattias Calmunger, Dr. Robert Eriksson and Prof. Sten Johansson. Paper I and Paper II have been a collaboration between the authors, although I have had the main responsibility for the modelling part in Paper II. In Paper VIII and Paper X, M.Sc. Jonas Saarimäki performed the investigation of the microstructure and cracking behaviour. In all other parts of the work presented in this dissertation I have borne the primary responsibility. 


\section{Contents}

Preface $\quad$ iii

Abstract $\quad$ v

Populärvetenskaplig sammanfattning vii

List of papers $\quad$ ix

Contents $\quad$ xi

Part I - Theory and background 1

1 Introduction 3

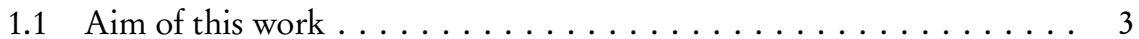

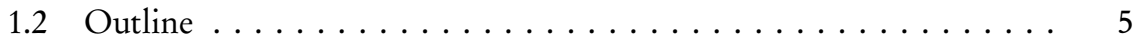

2 Superalloys 7

2.1 Composition and properties $\ldots \ldots \ldots \ldots \ldots \ldots$

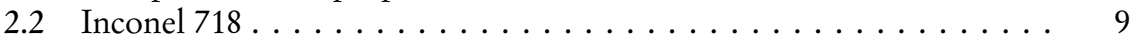

3 Fatigue 11

3.1 Crack initiation . . . . . . . . . . . . . . . . . 11

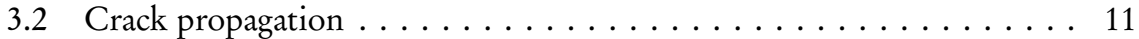

3.3 Crack closure and thresholds . . . . . . . . . . . . . . . . . . . . 12

3.4 Life prediction methods . . . . . . . . . . . . . . . . 13

3.5 Dwell time crack growth . . . . . . . . . . . . . . . . . . 14

3.6 Modelling of dwell time crack growth . . . . . . . . . . . . . . 15

4 Modelling work 21

4.1 Observations of dwell time damage . . . . . . . . . . . . . . . 21

4.2 Mechanical experiments ... . . . . . . . . . . . . . . 23

4.3 Brief model outline . . . . . . . . . . . . . . . 26

4.4 Areas of interest concerning dwell times . . . . . . . . . . . 26

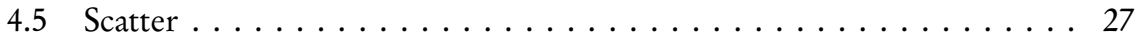

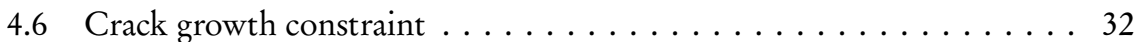


$5 \quad$ Review of appended papers $\quad 37$

6 Discussion and conclusions 43

7 Outlook 45

Part II - Appended papers $\quad 53$

Paper I: High temperature fatigue crack growth behaviour of Inconel 718 under hold time and overload conditions . . . . . . . . . . . 57

Paper II: Modelling of high temperature fatigue crack growth in Inconel 718 under hold time conditions . . . . . . . . . . . . . . . . . 79

Paper III: A load history dependent model for fatigue crack propagation in Inconel 718 under hold time conditions . . . . . . . . . . . . . . . 97

Paper IV: Modelling of fatigue crack growth in Inconel 718 under hold time conditions - application to a flight spectrum . . . . . . . . . . . . 119

Paper V: Crack length evaluation for cyclic and sustained loading at high temperature using potential drop . . . . . . . . . . . . . . . . . . 129

Paper VI: Three-dimensional crack growth modelling of a Ni-based superalloy at elevated temperature and sustained loading . . . . . . . . . 145

Paper VII: Modelling of crack growth with dwell time for aero engine spectra loadings in a Ni-based superalloy . . . . . . . . . . . . . . 165

Paper VIII: Scatter in dwell time cracking for a Ni-based superalloy in combination with overloads . . . . . . . . . . . . . . . . 179

Paper IX: Thermo-mechanical fatigue crack growth modelling in a Ni-based superalloy subjected to sustained load . . . . . . . . . . . . . . . 195

Paper X: Impact of high cycle fatigue on dwell time crack growth in a Ni-based superalloy . . . . . . . . . . . . . . . . . . 211 
Part I

Theory and background 



\section{Introduction}

A gas turbine interior, see Fig. 1, is one of the most extreme and hostile environments a material can be subjected to, with metal temperatures ranging all the way up to $1000^{\circ} \mathrm{C}$ in the hottest blade sections [1]. Since the first development of gas turbines, the goal has always been to strive for higher efficiency, which means elevating the turbine temperature. Further, future aero engines and stationary gas turbines will probably not be subjected to the same type of loading or environmental conditions as we are used to see them operate in today. Future engines must be able to handle, e.g., different types of fuels, as bio-fuels, or different load cycles, as the need for power output changes with the introduction of alternative power sources, as e.g. wind and solar power parks are not able to deliver constant power output at all times.

To handle these loading situations materials such as nickel based superalloys of various kinds are often used in combination with both internal and film cooling and thermal barrier coatings. Still, with these recourses the materials are often pushed to their mechanical degradation limits, which can cause disastrous engine failure. Being able to foresee failure in these highly critical structures is therefore of major importance. Further, most of the models that are used to predict when a component has reached its expected life are very conservative. To meet the strengthened requirements of gas turbine design, for both new and existing engine loadings, and to increase life prediction accuracy, the Swedish research programme TURBO POWER was formed, within which the work presented in this dissertation has been carried out. The programme is a joint collaboration between the Swedish Energy Agency, Siemens Industrial Turbomachinery AB, GKN Aerospace Engine Systems and several Swedish universities, with the objective to contribute to a sustainable and efficient global energy system in medium term and long term view by, see [2],

- efficiency improvements

- lower emissions

- better operation economy

- fuel flexibility, in particular regarding renewable fuels

\subsection{Aim of this work}

Safe life of gas turbines is always of major concern for manufacturers in order to ensure passenger safety and stable continuous power output. An increasing amount of 


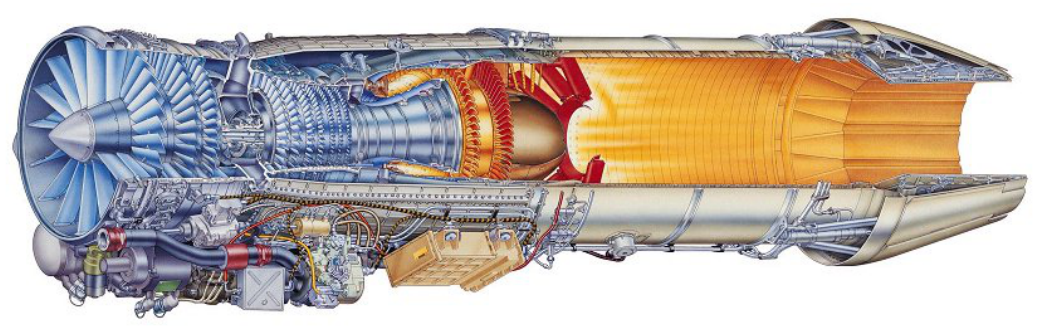

Figure 1: RM12 aero engine. Courtesy of GKN Aerospace Engine Systems.

resources have been put into research and development to assure that all safety aspects are covered in the design of a new turbine and to ensure that enough frequent service intervals are scheduled to avoid complications. Many of these issues require good knowledge of material properties and of how to consider these in the design process. Some of these relate to fatigue which is of major concern in all parts of a development programme. However, while some fatigue problems have been extensively studied, some have not, one example is crack growth under influence of dwell times at elevated temperature in combination with cyclic loading, cf. Fig. 2. Such loading conditions have been shown to give a different cracking behaviour compared to rapid cyclic loading, increasing the growth rate significantly with respect to the number of load cycles. Improved models for predicting this behaviour is therefore of major interest for gas turbine manufacturers, and could increase the reliability in major proportions. As a result, more research is needed in order to solve these problems.

The work presented in this dissertation has been done within the TURBO POWER project High temperature fatigue crack propagation in nickel-based superalloys, and focuses on how to predict life under the mentioned circumstances. In this dissertation the most common nickel based superalloy, Inconel 718, used in high temperature environments has been studied. Mechanical experiments have been performed for engine like conditions in order to receive material data and understanding of how the material responds to different types of loading situations. The main objective is: based on mechanical

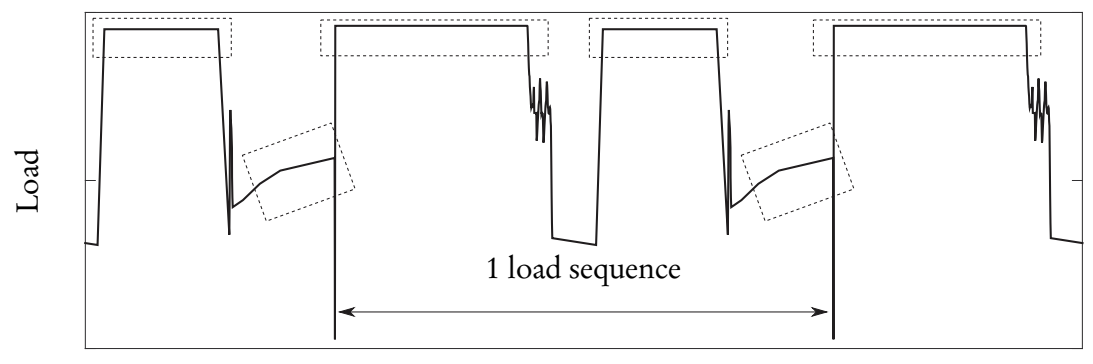

Time

Figure 2: Dwell times (dashed) and cyclic loading together in a flight spectrum. From Paper IV and Paper VII. 
experiments, develop a crack growth model applicable for industrial use with increased life prediction capabilities. Further, if the model is to be general and extendable as well as usable on a daily basis, it should be physically motivated and easy enough to understand for a user, thus a phenomenological approach should be chosen, with a minimum number of parameters for calibration.

\subsection{Outline}

The dissertation is divided into two parts, where first the theory and background of crack growth with dwell times is given, based on my Licentiate of Engineering thesis Modelling of fatigue crack propagation in Inconel 718 under hold time conditions from 2014.

The second part consists of 10 papers which represent the outcome of this work, which is a model that is both easy to use and which has shown good correlation to experimental data. In Paper II early model development was carried out. Other model components include calibration for cheap and easy parameter determination in Paper III, validation on complex engine spectra loadings in Paper IV and Paper VII, three dimensional crack growth in Paper VI, influence of overloads in Paper I and Paper VIII, material scatter in Paper VIII, thermo-mechanical fatigue crack growth in Paper IX, impact of high cycle fatigue loading in Paper $\mathbf{X}$, and experimental evaluation in Paper V. 



\section{Superalloys}

Designed to run under extreme heat, high stresses, oxidative and corrosive environments, often close to the melting temperature, superalloys have become a dominating alloy category within the gas turbine industry. In superalloys, one generally uses $\mathrm{Ni}$, Co or Ni-Fe as base materials [1, 3, 4]. Although all three types are found, it is mainly the $\mathrm{Ni}$ - or $\mathrm{Ni}-\mathrm{Fe}$ base alloys which have lately risen to be the primary choice among turbomachinery developers, since they have good properties and are relatively cheap [1]. It may be noted that over $50 \%$ of an aero engine's weight comes from these alloys [4]. Cost is also important when choosing between pure $\mathrm{Ni}$ and $\mathrm{Ni}-\mathrm{Fe}$ materials, as $\mathrm{Fe}$ is cheaper than Ni. However, it is to be noted that Fe has some negative influences, e.g. lowering of the oxidation resistance [1].

\subsection{Composition and properties}

Nickel is ductile and tough and gives good creep resistance [5], which is important, especially in high temperature environments. Often consisting of more than 10 different alloying elements, a superalloy is a very complex alloy, which in addition consists of many different phases. The main phase which all superalloys consist of is the matrix phase ( $\gamma$-phase); mainly consisting of $\mathrm{Ni}$, but also various other elements for solid solution strengthening, among them e.g. Co, Cr, Mo, Fe, W [4, 5]. The $\gamma^{\prime}$ phase $\left(\mathrm{Ni}_{3} \mathrm{Al}, \mathrm{Ti}\right)$ plays the role as principal strengthening phase in many superalloys. By adjusting the alloy content of e.g. $\mathrm{Ta}, \mathrm{Nb}$ and $\mathrm{Cr}$, the amount of the $\gamma^{\prime}$ phase can be altered [1].

In many $\mathrm{Ni}-\mathrm{Fe}$ alloys, $\mathrm{Nb}$ is also used, forming $\mathrm{Ni}_{3} \mathrm{Nb}, \gamma^{\prime \prime}$. This phase is in $\mathrm{Ni}-\mathrm{Fe}$ superalloys seen as the main strengthening phase instead of $\gamma^{\prime}$, as in pure Ni base alloys. However, $\gamma^{\prime \prime}$ is a metastable phase, and long exposure times, for Inconel 718 above

Table 1: Composition of some common superalloys in wt\% [5-7], see each respective manufacturer for more specific alloy content.

\begin{tabular}{llllllllllllll}
\hline Alloy & $\mathrm{Ni}$ & $\mathrm{Cr}$ & $\mathrm{Fe}$ & $\mathrm{Co}$ & $\mathrm{Mo}$ & $\mathrm{Al}$ & $\mathrm{Ti}$ & $\mathrm{Nb}$ & $\mathrm{W}$ & $\mathrm{Mn}$ & $\mathrm{Si}$ & $\mathrm{C}$ & $\mathrm{B}$ \\
\hline Haynes 230 & 57 & 22 & 3 & 5 & 2 & 0.3 & - & - & 14 & 0.5 & 0.4 & 0.1 & 0.015 \\
Haynes 282 & 57 & 20 & 1.5 & 10 & 8.5 & 1.5 & 2.1 & - & - & 0.3 & 0.15 & 0.06 & 0.005 \\
Waspaloy & 58 & 19 & 2 & 13.5 & 4.3 & 1.5 & 3 & - & - & 0.1 & 0.15 & 0.08 & 0.006 \\
Inconel 718 & 52.5 & 19 & 18.5 & - & 3 & 0.5 & 0.9 & 5.1 & - & 0.35 & 0.35 & 0.04 & 0.006 \\
Inconel 706 & 37 & 16 & 40 & 1 & - & 0.2 & 1.8 & 2.9 & - & 0.35 & 0.35 & 0.03 & 0.006 \\
Udimet 720 & 55 & 17.9 & - & 14.7 & 3 & 2.5 & 5 & - & 1.25 & - & - & 0.035 & 0.033 \\
\hline
\end{tabular}




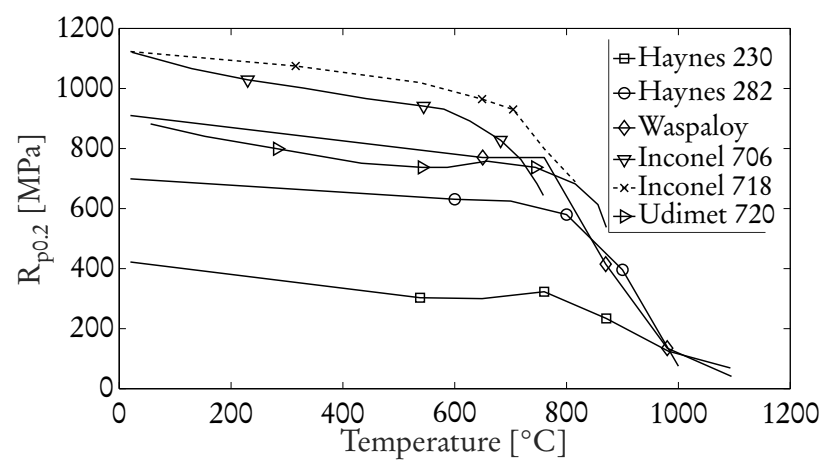

Figure 3: Yield strength for the alloy compositions in Table $1[6,7]$.

$650^{\circ} \mathrm{C}$, leads to the formation of the stable $\delta$ phase instead, with the same composition as $\gamma^{\prime \prime}$. This phase does not add strength, and is thus unwanted which means that the heat treatment has to be carefully monitored [4]. In addition to the phases mentioned above, $\mathrm{C}$ and $\mathrm{B}$ are added, in order to form various types of carbides and borides as $\gamma$ grain boundary strengtheners. For a more comprehensive discussion of the different phases, elements used for superalloy compositions, and superalloys in general, see $[1,3-5]$.

As understood, the different alloying elements will have different effects on the mechanical behaviour, e.g. yield strength, ductility, creep, fatigue life, manufacturing properties as e.g. welding, rolling, drawing, cutting etc., which makes it important to design for alloy compositions that can handle the situation it is supposed to be exposed to. Compositions can e.g. be good for one purpose but rather bad for another, e.g. an alloy with high yield strength required for turbine discs can lack the ductility properties required for the combustion chamber. Below some common superalloys compositions are listed, see Table 1, and as an example the yield strength as a function of temperature is shown in Fig. 3. As seen in Fig. 3, all alloys' yield strength degrade quickly at about $800^{\circ} \mathrm{C}$. Here the involved components must be designed with additional cooling

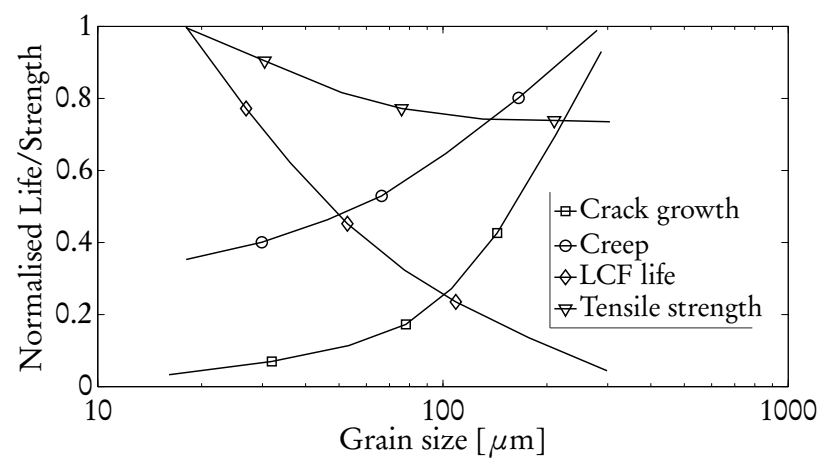

Figure 4: Life and strength with respect to grain size for Udimet 720. Adapted from [8]. 
and/or be coated with a thermal barrier coating, cf. [9], alternatively be made of other alloys that can withstand higher temperature. Also, keep in mind that the properties in Fig. 3 depend on the heat treatment and material type (e.g. wrought, cast, sheet, bar etc.), and should therefore only be considered as guidelines.

Other things can also affect the mechanical behaviour, e.g. grain size which can give a significant impact on fatigue life, strength, creep and dwell time damage resistance, see Fig. 4, and heat treatment, which can affect the phase distribution in the alloy to something unwanted, see e.g. [5] for more details.

\subsection{Inconel 718}

The superalloy studied in this project is the Ni-Fe based alloy Inconel 718, which is a frequently used alloy, representing almost half of the total tonnage of superalloys used worldwide [1], which for obvious reasons makes it an important alloy to investigate and to understand to its fullest. In Fig. 3 it can be seen that the alloy has excellent yield strength properties, which places it among the top performers among high temperature alloys. Its low price (relative to other alloys) and its very good manufacturing abilities and welding properties make this alloy outperform others in the same category. 



\section{Fatigue}

Components exposed to repeated loading are prone to fatigue failure. Much work to characterise the basic principles of fatigue have been done over the years since the introduction of the first railways. The first theories involving high cycle fatigue (caused by low load intensity) have progressed into the theories of low cycle fatigue (caused by higher load intensity), crack initiation and eventually crack propagation to extend life prediction accuracy even further. Predicting the life of a structure is of high importance as large costs are closely related to fatigue failure. Finding accurate models for describing the fatigue life must therefore be found in order to avoid the use of a too high safety factor. Below some basic principles are outlined regarding fatigue failure and how to deal with these. Nowadays research is being done in areas which have not been explored to their fullest and to improve models of already existing phenomena, this will be discussed in the upcoming sections.

\subsection{Crack initiation}

The first stage of metallic fatigue failure is when a crack is initiated in the material. The theory involves how local plastic deformation in the material gives rise to slip bands (dislocation pileup on the surface) in favourable crystallographic orientations (recall Schmid's law) in which the critical resolved shear stress (limit to cause plastic deformation) has been overcome. As repeated loadings are applied on the structure, a crack will eventually be formed and begin to grow, initially grain by grain (short crack growth). More comprehensive information and discussion about crack initiation and short crack growth can be found in e.g. [10].

\subsection{Crack propagation}

Eventually, when the crack has grown large enough to generate a larger amount of plasticity and has started to grow perpendicular to the loading direction (in the case of only a uniaxial tensile stress), local slip is still active (see above) and causes intrusions and extrusions of slip bands as the crack is cyclically loaded, i.e. multiple local slip at the crack tip. Each such repetition causes a so called striation and the crack is propagated forward, see e.g. [11].

Fatigue crack growth is for loadings well below the yield limit in most materials assumed to be a basically linear elastic process due to the very small plastic zone at the crack tip. The linear elastic fracture mechanics (LEFM) theory has been the dominating 
one due to its relative simplicity in creating acceptably accurate life predictions for most materials. Some exceptions are seen for very ductile materials with larger plastic zones, where other theories might apply (not discussed here). The LEFM theory is built on the stress intensity factor (SIF) $K$ which has proven its validity for many cases and is used for predicting life in many engineering problems. The stress intensity factor can be defined for three different load modes, namely tensile loading (I), in-plane shear (II), and out-of-plane shear (III), where the first (I) is considered to be the most important one and will completely define life for most materials and load cases. Consequently, only $K_{\mathrm{I}}$ will from now on be considered, see Eq. (1).

$$
K_{\mathrm{I}}=\sigma \sqrt{a \pi} \times f
$$

where $f$ is a geometrical factor depending on crack shape and type of loading. From the expression of the SIF in Eq. (1), Paris $[12,13]$ developed a method for determining the crack extension per load cycle, known as Paris' law, see Eq. (2). This expression is used in most crack propagation models, and also in the work presented in this dissertation.

$$
\frac{\mathrm{d} a}{\mathrm{~d} N}=C \Delta K^{n}
$$

\subsection{Crack closure and thresholds}

Most types of fatigue crack growth SIF ranges are affected by residual compressive stresses behind the crack tip, resulting in only a part of the SIF range being active during a fatigue cycle. The reasons of this can be many, but the most common one is plastically induced closure. Consequently, instead of generating a range of $\Delta K=K_{\max }-K_{\min }$, one is given an effective SIF range of $\Delta K_{\text {eff. }}=K_{\text {max }}-K_{\text {open }}$, i.e. part of the loading cycle does not contribute to the crack advancement. Using this effect is crucial when dealing with e.g. engine spectra as many different load ratios $\left(R=\sigma_{\min } / \sigma_{\max }\right)$ are present. Some models for this have been developed and implemented into crack growth programs such as NASGRO [14], where the model by Newman [15] is perhaps the most recognised one for industrial use, and which has here been effectively used in Paper IV, Paper VI, Paper VII and Paper IX where different spectra have been analysed.

Further modifications such as compensation for when the SIF is small can also be introduced. Crack growth has been seen to start only above a specified threshold value $K_{\mathrm{th}}$. This value is also usually dependent on temperature and load ratio, and one can for cyclic loading disregard any growth below it, cf. [16] for further discussion.

An upper limit of the SIF can also be introduced. As the SIF increases and closes up on the fracture toughness value, $K_{\mathrm{c}}$, the growth rate has been seen to increase above the rate predicted by Paris' law. Models for compensating both for the threshold value and the fracture toughness can be found in e.g. [14], where comprehensive discussions about modelling approaches can be found. The use of $K_{\mathrm{th}}$ is also discussed in Paper X.

The whole concept of crack propagation is presented in in Fig. 5, where the typically observed regions of the fatigue crack propagation for metals are seen. Note the Region I with the threshold value, Region II in the middle, commonly known as 


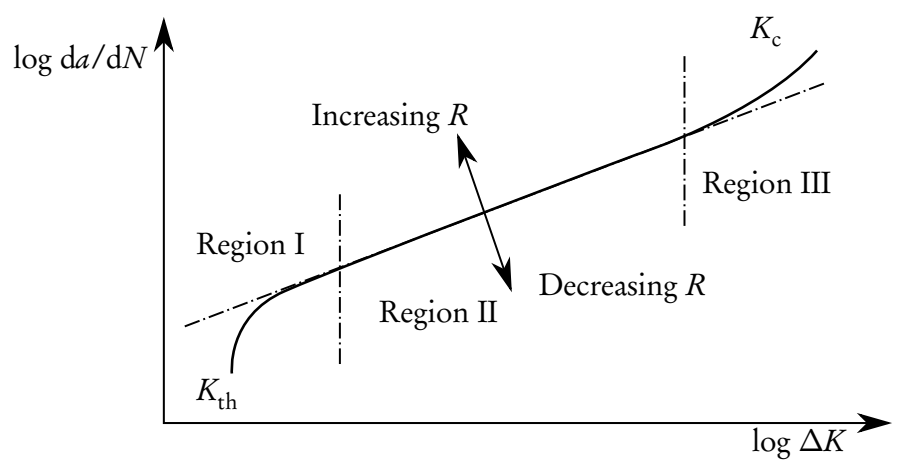

Figure 5: Fatigue crack propagation curve with the different regions commonly seen for most metallic alloys. Load ratio $R=K_{\min } / K_{\max }$.

the Paris-region [12, 13], and Region III where the influence of the fracture toughness is seen. The field of fracture mechanics is huge, and the reader is referred to, e.g., [14] for a more comprehensive discussion of other influencing factors, e.g. overloads. In later years the attention has been placed on predicting fatigue crack growth in arbitrary structures, which is typically handled by contour integrals, e.g. the $J$ integral or variants of its formulation, cf. [17].

\subsection{Life prediction methods}

Many manufactured components have defects or stress concentrations at notches which can, by long or short term use, initiate a crack, which may eventually propagate to failure. Even if a good manufacturing process has been chosen, the material can always show defects. Good materials which normally give long life, can by defects give designs with strongly reduced life. One such example is welds, where the scatter in life is substantial. Fatigue will of course generate very complex problems, where every modelling parameter becomes important. Large errors will be introduced if e.g. a correct life prediction model of the material behaviour is absent, which in turn will affect the economical aspect of the situation.

Since scatter is a large factor to consider in fatigue, the importance of having a correct life prediction model can only show itself if multiple tests from several different material batches are being investigated. To take this aspect into consideration is of major importance before taking a newly developed method into industrial use. In Paper III, Paper VII and Paper IX, examples of this are shown, where several batches are being investigated and simulations are being performed.

A complete life assessment does, however, not only focus on the crack propagation prediction of a component's life, many other aspects must be considered. The use of a non-destructive inspection method, e.g. liquid penetrant or x-rays, on components to see if a crack has been initiated or how long it has grown is often applied. The prediction of how long service life that remains can thereby be updated, or a retirement 
of the component can be suggested. Crack initiation and propagation simulations are often performed together in order to improve life prediction even further.

Probabilistic methods are also used to ensure that the component lies below a given risk of failure, often set to $0.1 \%$ (about $-3 \sigma$ ). One example of this can be found in Paper III where the scatter of 22 tests from 2 batches has been studied.

Consequently, it becomes apparent that accurate life prediction models are necessary, when considering both safety and cost.

\subsection{Dwell time crack growth}

As previously mentioned in this chapter and in the introduction of this dissertation, an increase in simulation accuracy for existing life prediction tasks is always desired. As a result, the project has focused on describing and modelling the dwell time crack growth phenomenon which is frequently seen in gas turbine applications. Improving the models for this will significantly increase the accuracy of life expectancies of involved components and may reduce service intervals etc.

A majority of the fatigue crack propagation problems analysed today concern rapid cyclic loading. However, there are a significant number of situations in which this is not the case. For many gas turbine applications, high temperature dwell time loading can be seen during many different parts of the load cycle. Dwell times can be seen as slowly applied loads or sustained loading, which can for some materials not only give rise to a time dependent crack growth but also impose a completely different crack growth behaviour. The lack of reliable models in this area is the main objective behind this research, as a model which is able to predict this behaviour will be of great interest for industry as well as for academic purposes. The outline of the following sections will therefore concern the effect itself and the development of fatigue crack propagation models aiming at describing it.

\section{Dwell time damage}

Dwell times can increase the crack growth rate substantially. The effect is seen for a number of different materials in many high temperature applications, e.g. low-alloyed steel [18], Inconel 100 [19], Inconel 718, 706, 783, Udimet 720 and Waspaloy [20-25]; all for various temperatures and lengths of sustained load. Further, in e.g. [26, 27] a characterization of how loading frequencies influence the dwell time behaviour of Inconel 718 was made with a triangular wave which showed that not only sustained loading gave dwell time effects, which further emphasises the importance of being able to predict the phenomenon. For some examples see Fig. 6, where in Fig. 6(a) results for various dwell times at $550^{\circ} \mathrm{C}$, and in Fig. 6(b) results for $2160 \mathrm{~s}$ dwell time tests at several different temperatures are shown; all for Inconel 718.

In the above-mentioned works, and many others, the main discovery is that the crack, on a microscopic scale, grows in an intergranular fracture mode. This is different from cyclic fatigue crack growth, with enough high frequency to eliminate the dwell time effect, where mainly transgranular fracture is seen. Clearly this indicates that by 


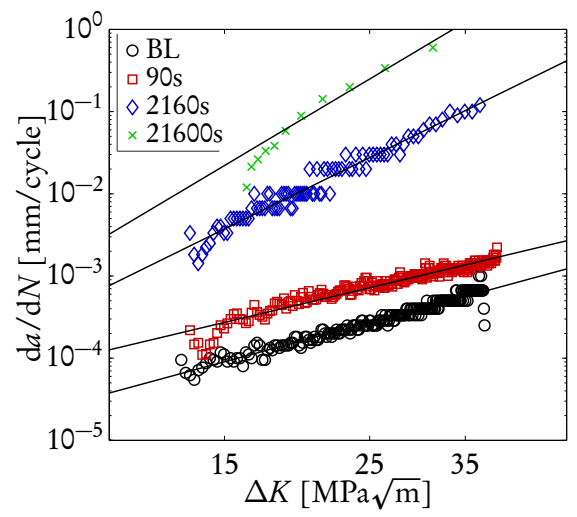

(a)

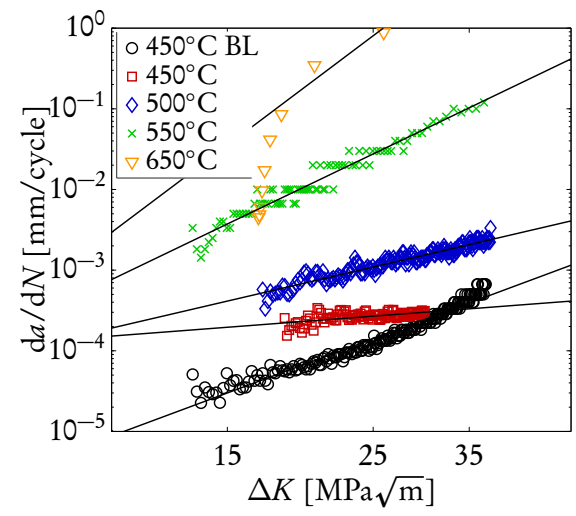

(b)

Figure 6: Dwell time crack growth rate. (a) Different dwell times compared to baseline loading for $550^{\circ} \mathrm{C}$ and (b) $2160 \mathrm{~s}$ dwell time tests for several different temperatures including 1 cyclic test $(\mathrm{BL})$ at $450^{\circ} \mathrm{C}$ for comparison purposes.

the dwell time exposure the grain boundaries have been weakened by some kind of damage mechanism.

Other experiments have revealed that cracking is strongly affected by the environment, e.g. vacuum vs. oxygen, where it has been shown that a significant reduction in crack propagation rate is found in vacuum, see Fig. 7 and e.g. [28-34]. These tests and observations clearly show that the grain boundaries have been affected by some sort of damage mechanism which is not active during rapid cyclic loadings.

\section{Damage theories}

Based on these observations, theories for how this cracking phenomenon occurs have been developed. Authors have tried to describe the mechanism and how it affects the grain boundaries, and two dominating theories have been developed, namely dynamic embrittlement (DE) and stress accelerated grain boundary oxidation (SAGBO), describing different ways in which oxygen (among other embrittling elements) affects the grain boundaries. DE is a cracking process where embrittling elements (e.g. oxygen) weaken the grain boundaries, and allow for further crack advancement, see e.g. [18, 22, 32]. SAGBO involves oxidation of grain boundaries and the subsequent cracking of these oxides, allowing for further crack advancement, see e.g. [33].

\subsection{Modelling of dwell time crack growth}

The modelling of dwell time crack growth has been attempted by many authors. Most of them, e.g. [19, 29, 35-38], rely on an additive description, where the contributions from dwell times and cyclic loads are added together without any history dependence, 


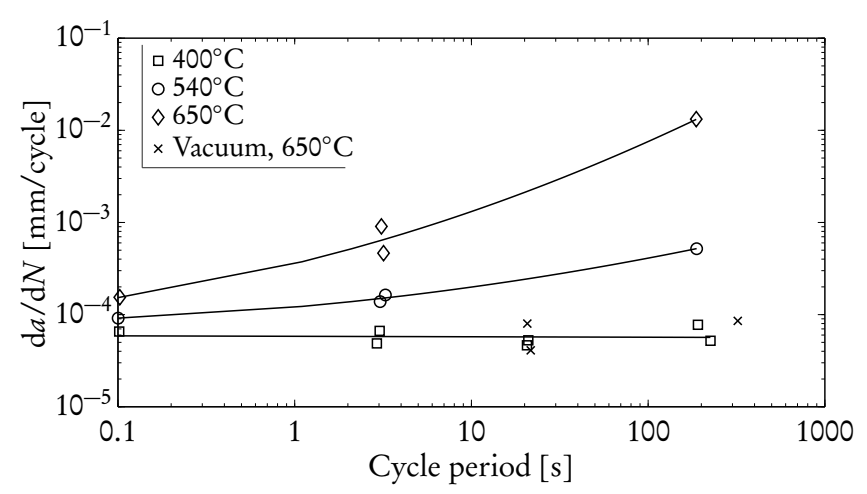

Figure 7: Crack growth rate for dwell times for constant SIF $(27.5 \mathrm{MPa} \sqrt{\mathrm{m}})$ for Inconel 718 at different environments. Adapted from [30].

see Eq. (3). Other models are based on physically motivated equations for e.g. diffusion, damage, crack closure, creep, alloy composition etc., where sometimes FE computations have been used/are needed for parameter determinations. Examples of such models can be found in e.g. [39-44]. These models can prove useful in the description of a dwell time cycle, as they will also in some cases include history effects. However, the implementation and use of such models can require a high threshold in understanding for an everyday engineering problem, not to mention the time effort to calibrate the models by e.g. nodal release routines.

$$
(\mathrm{d} a)_{\text {tot. }}=\frac{\mathrm{d} a}{\mathrm{~d} N} \mathrm{~d} N+\frac{\mathrm{d} a}{\mathrm{~d} t} \mathrm{~d} t
$$

Some of the existing models will now briefly be presented. Emphasis is put on describing the basic features of the models, for details of e.g. the different parameters and how they can be determined the reader is referred to their respective original source.

\section{Model by Saxena}

The model by Saxena [35] (see also [45, 46]), has been developed with respect to three crack growth regimes: (1) fully cycle dependent region, (2) intermediate region where both cyclic loads and dwell times affect the total crack growth rate, and finally (3), the fully time dependent region, i.e. the crack growth is only affected by time dependent cracking. The model, which has been tested for various dwell times, is given by Eq. (4) for Region (2), while the cyclic dependent Region (1) is given by an ordinary Paris law expression. When to apply the different crack growth region laws, is given by the transitional loading frequency, which is determined from experimental evaluation.

$$
\frac{\mathrm{d} a}{\mathrm{~d} N}=C_{1}(\Delta K)^{n_{1}}+C_{2}(\Delta K)^{n_{2}}\left(\sqrt{t_{\mathrm{h}}}\right)
$$


where $n_{1}, n_{2}, C_{1}, C_{2}$ are fitting constants, $t_{\mathrm{h}}$ is the dwell time. For a fully time dependent loading, Region (3), the following equation is used:

$$
\frac{\mathrm{d} a}{\mathrm{~d} N}=t_{\text {hold }} C_{\text {time }} K^{n_{\text {time }}}
$$

\section{Model by Gayda et al.}

Another linear summation model was proposed by Gayda [29], which is similar to the one by Saxena [35], see Eq. (6). The model has capabilities to handle slow ramp-ups to the sustained load level, i.e. dwell time damage is not only included in the sustained loading.

$$
\frac{\mathrm{d} a}{\mathrm{~d} N}=B \Delta K^{m}+A \Delta K^{n}\left[Z /(\nu(n+1))+t_{\mathrm{hold}} /(1-R)^{n}\right]
$$

where $Z=\left(1-R^{n+1}\right) /(1-R)^{n+1}, R$ is the load ratio, $A, n, B, m$ are Paris parameters for time dependent and cyclic loading respectively, $t_{\text {hold }}$ is the dwell time of a cycle, and where finally $\nu$ is the loading frequency of the ramp up to and down from the sustained load level.

\section{Model by Kruch et al.}

An LEFM-based modelling approach where the material parameters are calibrated by FE simulations has been suggested by Kruch [41]. Here a non-linear time dependent constitutive law is used to find closure parameters for various types of load cycles by a nodal release approach. The model is in its simplest form seen in Eq. (7). As seen, the model is a cycle per cycle linear summation model, thus introducing a load history dependence, where, e.g. overloads or (oxidation from) dwell times, will affect the crack opening value obtained from numerical analysis.

$$
\mathrm{d} a=C_{\mathrm{F}}\left[K_{\mathrm{M}}-K_{\mathrm{S}}\right]^{\eta_{\mathrm{F}}} \mathrm{d} N+C_{\mathrm{c}}\left[K_{\mathrm{t}}-K_{\mathrm{S}}\right]^{\eta_{\mathrm{c}}} \mathrm{d} t
$$

where $C_{\mathrm{F}}, C_{\mathrm{c}}, \eta_{\mathrm{F}}, \eta_{\mathrm{c}}$ are material parameters, $K_{\mathrm{M}}$ is the maximum SIF value during a load cycle, $K_{\mathrm{S}}$ is the threshold value influenced by overloads, underloads, dwell times etc. and obtained from the crack closure calibration (updated after and before a fatigue cycle) and $K_{\mathrm{t}}$ is the SIF value during a dwell time load. Examples of application to load spectrums and further explanations are found in $[40,41]$ where the model is extended to non-isothermal conditions and in [47] where the same model has been applied for the single-crystal superalloy AM1.

\section{Model by Evans and Saxena}

The model by Evans and Saxena [44, 48], also discussed in [46], and given by Eq. (8), consists of a number of parameters which will account for most mechanisms believed 
to affect dwell time damage.

$$
\begin{aligned}
& \left(\frac{\mathrm{d} a}{\mathrm{~d} N}\right)_{\text {tot. }}=q \Delta K^{n_{1}}+c_{0} \Delta K^{\mathrm{m}_{0}+\frac{c_{1}}{R T}} \exp \left(-\frac{Q_{0}}{\mathrm{R}_{\mathrm{G}} \mathrm{T}}\right) \\
& +\int_{0}^{\mathrm{t}_{b}} A^{\prime \prime} \exp \left(-\frac{\mathrm{Q}}{R_{G} T}\right) \exp \left[\Psi^{\prime}\left(\frac{1}{T}\right)\left(\frac{1}{t}\right)^{\frac{1}{\mathrm{n}+1}}\left(\frac{\Delta K}{1-R}\right)^{\frac{2}{\mathrm{n}+1}}\right] \mathrm{d} t
\end{aligned}
$$

where $q, n_{1}, \Psi^{\prime}, n$ and $A^{\prime \prime}$ are constants, $t$ is the time for a cycle, $Q_{0}$ is the thermal activation energy of dislocations, $R$ is the load ratio, $Q$ is the activation energy between the environment and the alloy, $R_{G}$ is the universal gas constant, $T$ is the temperature, and finally $t_{\mathrm{h}}$ is the dwell time. All the different parameters can be derived from four different tests at different conditions, e.g with different environments, temperature and loading frequency.

\section{Model by Ghonem and Zheng}

The model by Ghonem and Zheng [38] is based on the intergranular oxygen diffusion depth at the crack tip, which is dependent on the oxygen diffusivity of the grain boundaries, see Eq. (9). As a result, the model takes a more physical approach than the earliest linear summation models. Nevertheless, it is still a non-history dependent one, in contrast to e.g. the one by Kruch [41].

$$
\begin{aligned}
& \left(\frac{\mathrm{d} a}{\mathrm{~d} N}\right)_{\text {tot. }}=\frac{\mathrm{d} a}{\mathrm{~d} N}+\frac{\mathrm{d} a}{\mathrm{~d} t} \\
& \frac{\mathrm{d} a}{\mathrm{~d} t}=\frac{\mathrm{d} a}{\mathrm{~d} N}+\int \dot{X}(\Delta K, t) \mathrm{d} t \\
& \dot{X}=G_{1}(t) \Delta K^{\mathrm{m}} \\
& G_{1}(t)=A t^{-a_{1}} \exp \left(-\frac{a_{2}}{t}\right)\left(1-a_{1}+\frac{a_{2}}{t}\right)
\end{aligned}
$$

where $m, A, a_{1}$ and $a_{2}$ are coefficients to be set.

\section{Model by Chan et al.}

The time dependent cracking model by Chan et al. [49], is based on an Arrhenius function, see Eq. (10) valid for constant frequency with dwell.

$$
\begin{aligned}
& \left(\frac{\mathrm{d} a}{\mathrm{~d} N}\right)_{\mathrm{dwell}}=\left(\frac{\mathrm{d} a}{\mathrm{~d} N}\right)_{\text {cyclic }}+\left[t_{\mathrm{dwell}}+1 / f\right]\left(\frac{\mathrm{d} a}{\mathrm{~d} t}\right) \\
& \left(\frac{\mathrm{d} a}{\mathrm{~d} N}\right)=A \Delta K^{n} \quad \Delta K>\Delta K_{\mathrm{th}} \\
& \left(\frac{\mathrm{d} a}{\mathrm{~d} t}\right)=\underbrace{B_{0} \exp \left(-\frac{\mathrm{Q}}{R T}\right)}_{B} K^{m}
\end{aligned}
$$


where $t_{\text {dwell }}$ is the dwell time, $f$ is the loading and unloading frequency, $A, n, B_{0}$ and $m$ are constants, $R$ is the universal gas constant, $Q$ is the activation energy, and, finally, $T$ is the absolute temperature.

\section{Model in NASGRO}

Two time-dependent models are available in NASGRO [14], first a Paris model with time-dependent parameters, see Eq. (11), and the second an exponential function yielding almost the same result. For a more comprehensive comparison, see [14].

$$
\frac{\mathrm{d} a}{\mathrm{~d} t}=A K^{n}
$$

Both equations are stated to be valid for predicting the time-dependent behaviour in glass structures, e.g. windows and optical lenses.

\section{Comparison between models}

The models discussed above are all developed for short dwell times and often require special tests for calibration, sometimes in vacuum (tests required have not been performed within the testing programme executed in the work presented in this dissertation), or measurements of relaxation and crack opening by nodal release routines etc. As a result, none of them have been implemented and tested in this work, with the exception of the linear summation model in Eq. (3), which has been used for comparison purposes in Paper IV and Paper VII.

\section{Summary}

A first comment might be that the functions based on pure LEFM criteria are the most widely used. However, most of the models presented above are investigated for relatively short dwell times and do not incorporate any history dependence, thus they are physically questionable, and those who do may be too time-consuming in calibration due to e.g. FE usage. Questions should therefore be raised, how a model based on pure LEFM can be modified so that a history dependence of the dwell time effect can be incorporated. 



\section{Modelling work}

In the aim of the project some basic rules were set up (see the introduction of this dissertation), and how to fulfil all of these had to be kept in mind when developing the modelling concept. A reliable model that can be applicable for everyday use by a stress engineer, which is computationally not too costly, and which is easy to calibrate, should be of high value for any industry and academy for continuous research. The modelling concept has been designed so that additional modules can be added even after this project has reached its end. Consequently, the basics have been laid on designing a model with the use of LEFM and physically motivated parameters for describing the dwell time crack growth effect.

\subsection{Observations of dwell time damage}

It was from test specimen analyses of dwell time tests observed that potential drop (PD) measurements did not coincide with the final crack length on the fracture surface upon breaking of test specimens, see e.g. Paper V. In addition, it was also observed that an increase in crack growth rate compared with baseline loading was obtained when initiating a rapid cyclic block after a sustained loading, see Fig. 8 and Paper II. These observations have also been done in other studies of the past decades, see e.g. $[19,24,30]$ among others, indicating that some parts of the fracture surface is damaged to some extent, but still electrically conductive [50] and non-visible by compliance measurements [19].

The region in which damage has taken place, is here, and in other works (see above), referred to as the damaged zone. Further, its length will here be labelled $D$, see Fig. 9. Keeping track of $D$ should provide a possibility for describing the dwell time damage effect on the crack growth rate, as the history of how the crack grows is intimately connected to the build-up and destruction of the damaged zone. This approach was chosen as a suitable concept for the crack growth modelling carried out within this work, see e.g. Paper III.

Observations of the damaged zone on post-mortem fracture surfaces are not easily carried out. The damaged, but still electrically conductive parts of the material are visible by PD distance on the post-mortem fracture surface, but not explicitly seen on the fracture surface itself in e.g. a scanning electron microscope (SEM). The reason is that, as the damaged mechanism to some extent is affecting the grain boundaries throughout the damaged zone, they are broken intergranularly upon breaking of the test specimens, which gives the difficulty of actually physically seeing the damaged 


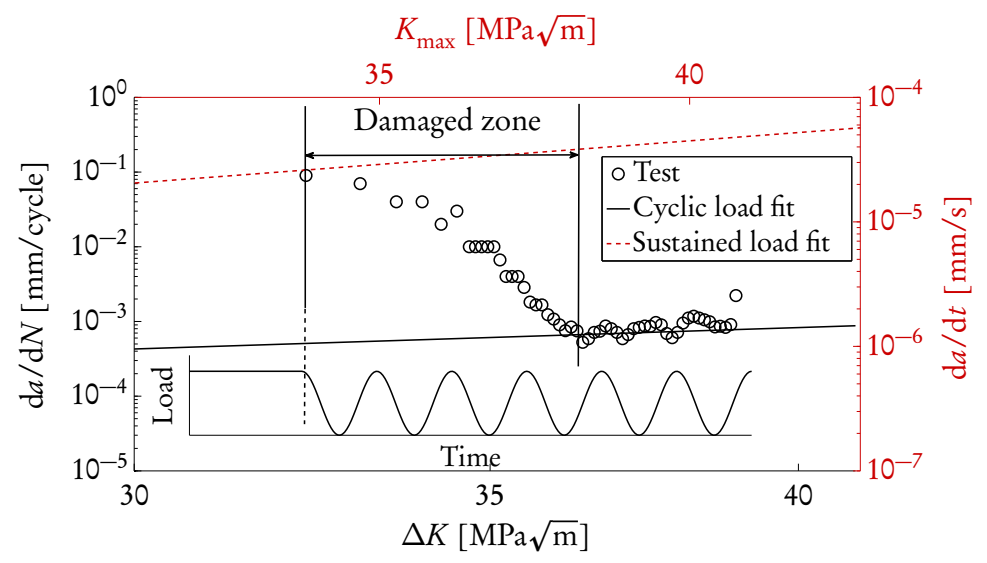

Figure 8: Damaged zone consumption in the transition from sustained to cyclic load. From Paper VI.

zone. In other studies, cf. [51], an unbroken corner crack specimen was used to create a three-dimensional fracture surface, where it was shown how the damaged zone actually looks. A study of some dwell time tests and investigation of the damaged zone on the fracture surfaces was performed in Paper V, where it was shown how some less affected stronger grain boundaries in the damaged zone still broke in a ductile fashion at final rupture, thus showing a discrepancy between the PD and the final fracture surface. The existence of more preferred grain boundaries for dwell time damage has also been seen in other studies, see e.g. [52].

Consequently, due to the difficulty of physically observing the damaged zone, a simplification has to be made. It was proposed from the beginning that the crack length observed by PD should serve as the governing crack length in the modelling work. The distance from the crack length by PD to the final crack length on the fracture surface serves as the damaged zone distance $D$. These 2 measurements together, $a+D$, gives the microstructural crack length (distance to unaffected material) seen at final fracture. The simplified approach adopted provides for a practical model development environment, see Paper V for further discussion. In Fig. 9 the way the crack length and damaged zone relate to the microstructural crack length is shown.

It should be noted that in all modelling work presented in this dissertation, the area which can carry load is the one not defined by PD, i.e. the damaged zone is not part of

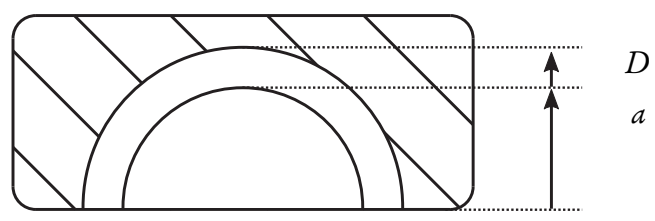

Figure 9: Crack length $a$ and damaged zone $D$ which together forms the microstructural crack length seen on the final fracture surface. Adapted from Paper V. 
the crack length itself, but rather seen as a concept to provide for history dependence.

\subsection{Mechanical experiments}

\section{Test set up}

To investigate the effect of the damaged zone and to find out how to incorporate it into the modelling concept etc., some mechanical testing were carried out. In all papers the experiments were carried out on Kb-type specimens with a pre-defined notch from electro discharge machining (EDM) under load control, except for a few tests, cf. Paper IX, where notched specimens were used under strain control and varying temperature, see [53] for a more detailed description. The reason for choosing Kb-type specimens was that the most commonly seen crack type is industrial applications could be studied, namely surface cracks. These cracks have been shown to occur in most components contrary to e.g. through cracks. One must, however, keep in mind that other test specimen types might be beneficial for other reasons, e.g. for examining the effect of plane strain/stress relations.

\section{Crack monitoring and evaluation method}

In the studying of surface cracks one must know how long the crack is, or more specifically, the cracked area. Monitoring these cracks can therefore be more difficult than crack types that can be optically studied by e.g. a camera. As mentioned in the previous section, potential drop (PD) measurements were used using direct current. This method basically consists of running a current, in this case pulses of $12 \mathrm{~A}$, through the specimen and measuring the potential drop as the cracked area increases. Two wires ( 1 on each side) were therefore welded next to the EDM notch. In addition two reference wires were welded on the back of the specimen to serve as a normalisation value in order to reduce scatter. In Fig. 10 the set up of the PD measurement is shown, where it can be seen how the welds are placed on the test specimen.

To evaluate the PD data in order to receive an equivalent crack length, some different methods can be used; either to calibrate the data to the post-mortem fracture surface that can be received from each test, or as in this case, to calibrate every test to a pre-defined calibration curve. This curve was defined from a cyclic test and enables the evaluation of the damaged zone length (as it is electrically conductive). It has been shown from evaluations that by applying this method the most accurate measurements of the crack length over time could be received, see e.g. Paper V, at least when a test is being subjected to dwell times. It is to be kept in mind that one disadvantage of this method is that only 1 crack length measure is received, i.e. for increased accuracy, 2 or more growth directions would be preferred. Further discussion of this matter can e.g. be found in Paper VII and Paper VIII. 


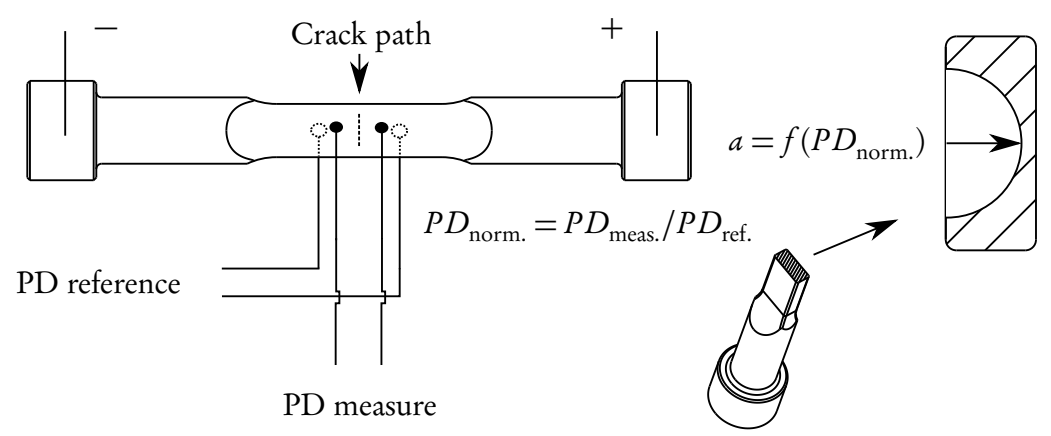

Figure 10: Schematic set up for measuring crack length in a Kb-type test specimen where the equivalent crack length $a$ is derived from the normalised PD signal.

\section{Mechanical tests}

Throughout the work presented in this dissertation many different test types have been used, for characterisation of the material response to dwell times, and/or for continuous model development, see below.

- Cyclic tests, i.e. baseline tests to receive growth rates for a crack without dwell times.

- Sustained load tests for establishing stabilised dwell time growth rates.

- Dwell time tests of various lengths for seeing the effect of load reversals.

- Dwell time tests with initial overloads to see the effect on the damaged zone development.

- Block tests to investigate the damaged zone length and how it is affected by rapid load reversals.

- Block tests with overloads to see the effect on the damaged zone development.

- Mixed tests with cyclic loads and dwell times for model calibration.

- Spectrum tests for model validation.

- Thermo-mechanical fatigue (TMF) tests under strain control and varying temperature for validation purposes.

- Superimposed high cycle fatigue (HCF) loads on dwell time tests to simulate non-ideal engine conditions.

A more detailed overview is presented in Table 2, where each test type and the corresponding paper are presented, either in the form of experimental work, modelling work, or both. 


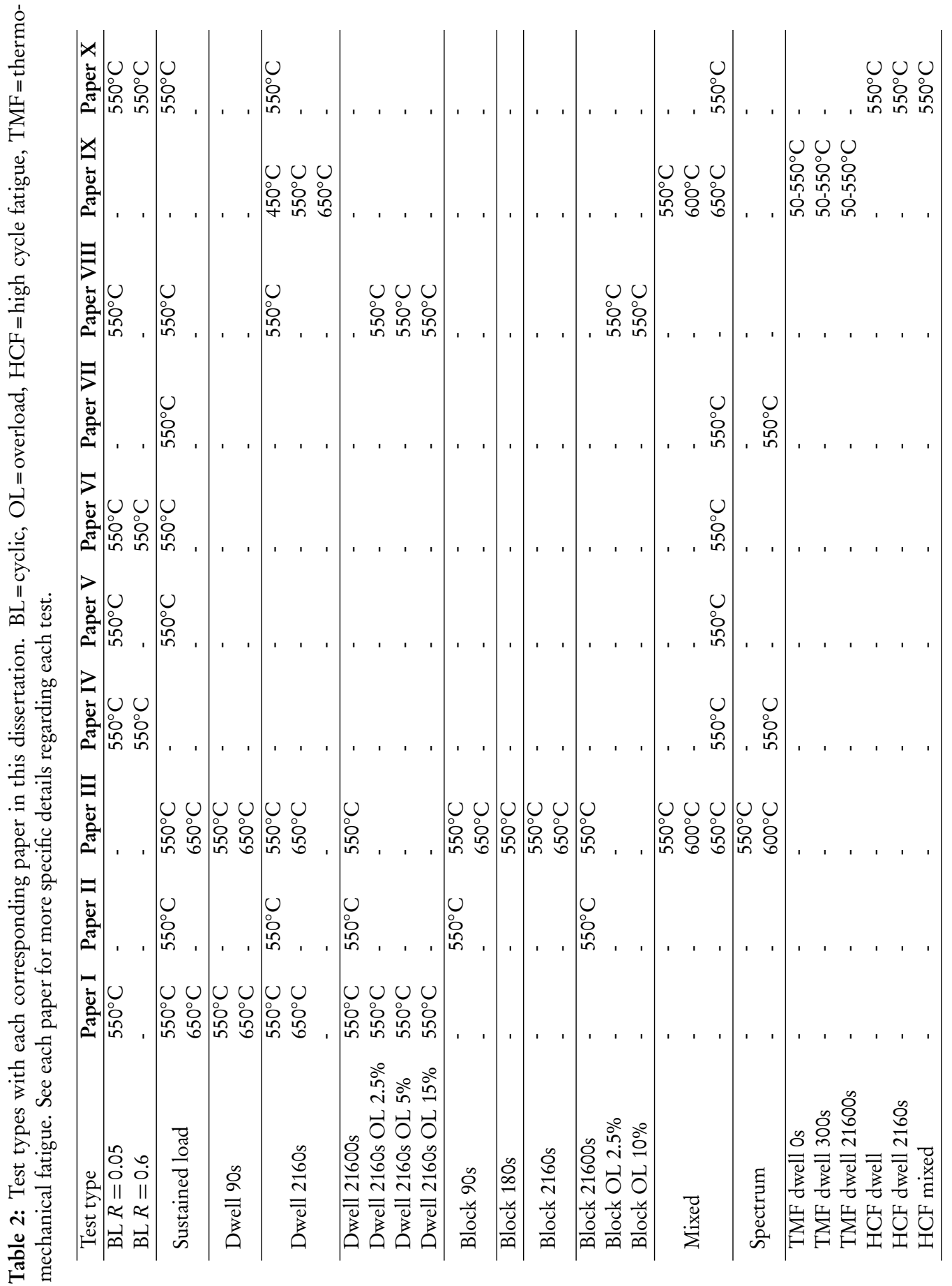




\subsection{Brief model outline}

The model which has been developed can briefly be explained as a time dependent part where the crack growth is controlled by $K_{\max }$ and the length of the damaged zone $D$, and a cyclic part, controlled by $\Delta K$ and the damaged zone length $D$, where the crack growth rate is increasing when there exists a damaged zone, cf. Fig. 8.

Regarding the time dependent part, it has been seen in many studies, cf. [18, 32, 54] and Paper III, that for sustained load crack growth it takes some time to reach the stabilised growth rate value. As a result, it was proposed that the growth rate itself should depend on the damaged zone length, unlike traditional models which assumes fully developed growth rates from the beginning (see the previous chapter). A growth rate $\dot{a}_{\mathrm{t}}$ for the time dependent part was therefore constructed as, $\dot{a}_{\mathrm{t}}=f\left(C_{0 \mathrm{t}}, n_{\mathrm{t}}, B_{\mathrm{t}}, D, D_{\max }, K_{\max }\right)$, where $B_{\mathrm{t}}$ is a fitting parameter, $D$ is the damaged zone length and $D_{\max }$ is the damaged zone length at stabilised growth. The parameters $C_{0 t}$ and $n_{\mathrm{t}}$ are the stabilised power law parameters for dwell time crack growth. For the time dependent part, the growth rate is increasing with respect to $D$ until the value of $D_{\text {max }}$ is reached (asymptotically).

The cyclic growth rate was modelled as, $\dot{\mathrm{c}}_{\mathrm{c}}=f\left(C_{\mathrm{c}}, n_{\mathrm{c}}, A_{\mathrm{c}}, B_{\mathrm{c}}, D, D_{\max }, \Delta K\right)$, where $A_{\mathrm{c}}$ and $B_{\mathrm{c}}$ are fitting parameters while $C_{\mathrm{c}}$ and $n_{\mathrm{c}}$ represent the baseline parameters for cyclic growth.

The two parts interact with each other depending on the load spectrum, i.e. the damaged zone length varies depending on the load history, and so does the crack growth rate, see e.g. Paper III.

From these expressions it can be seen that there exist 8 parameters to be calibrated. However, all of them can be extracted from one single test type, namely the mixed test type mentioned in the list of test types above and in Table 2. This makes the model easy enough to handle from an industrial perspective as well, where the time limits are often tight. It may be noted that these parameters are sufficient for the model "as is". On the other hand, if e.g., crack closure (see Paper IV, Paper VI, Paper VII and Paper IX), three-dimensional crack growth (see Paper VI), TMF crack growth (see Paper IX) or HCF crack growth (see Paper $\mathbf{X}$ ) is to be dealt with, a few further special parameters must be added.

\subsection{Areas of interest concerning dwell times}

Besides the basic modelling of dwell time effects and cycle interaction, see Paper II and Paper III, some additional areas have been of interest in the project. These include some of the most common features seen in gas turbine engine spectra, as briefly outlined above.

A gas turbine is usually subjected to varying load ratio, which makes it necessary to include corrections for crack closure. Closure corrections and how well the model can predict realistic engine spectra have been studied in Paper IV. In Paper VII some engine spectra were investigated which also include dwell times of non-sustained load type. 
Overloads have been seen to affect the dwell time effect dramatically and have been studied in Paper I and Paper VIII. Some discussions about the phenomenon are given, and the topic was also further investigated in [55].

With increased computational resources, the gas-turbine industry is also becoming more interested in treating three-dimensional crack growth. Consequently, how to handle dwell time modelling in a general context has been studied in Paper VI.

Aspects regarding stress concentrations and varying temperature have been studied in Paper IX, where the tests were subjected to strain control as opposed to stress control as in the other papers.

There was also a need of investigating how vibrations affect dwell time crack growth, as this has not been frequently studied before. As a result, Paper $\mathbf{X}$ has been dedicated to this issue, where the modelling concept yet again proves itself useful with the development of an additional module.

The evaluation of crack growth specimens which have been subjected to dwell time was studied in Paper V. How to evaluate the damaged zone length and how to subsequently incorporate it into subsequent modelling is of high importance. The reasons for choosing the evaluation method in the project is discussed more in depth in this paper.

\subsection{Scatter}

In the project different test types were used, see Table 2. Due to limited resources within the project a maximum of one, or a couple of tests of the same type could be carried out. This will of course limit the possibilities to examine the material scatter within a specific test type. However, as material scatter is an issue of high importance when fatigue is regarded and as the project has spanned over a significant amount of time, several different material batches have been made available for testing, which have been used to study scatter.

\section{Material batches}

During the first phase of the TURBO POWER programme, from 2007 to 2011, a substantial amount of experimental data was produced see e.g. [56]. These results have been made available for this second phase of the programme (2012 to 2015), which has given a significantly larger population of tests to use for model development. In Phase 1 of the programme, 1 batch of material of fine grained Inconel 718 was used, while in the second phase, 2 additional batches have been used for manufacturing of test specimens (also fine grained Inconel 718). All of these 3 batches originate from bar material. In addition to these batches, 1 batch of wrought Inconel 718, taken from a turbine disc, has been used. Tests from this batch were reported in [53] and used in Paper IX in this dissertation.

It was also shown that the material scatter was significantly larger from batch-tobatch than within the batches themselves, and this has been used to give the model a further justification. With the use of batch to batch comparisons, factors such as the 
Table 3: Alloy content in $\mathrm{wt} \%$ for the material batches used in the project. Data from material certificates.

\begin{tabular}{llllllllllll}
\hline Batch & $\mathrm{Ni}$ & $\mathrm{Cr}$ & $\mathrm{Fe}$ & $\mathrm{Co}$ & $\mathrm{Mo}$ & $\mathrm{Al}$ & $\mathrm{Ti}$ & $\mathrm{Nb}$ & $\mathrm{Si}$ & $\mathrm{C}$ & $\mathrm{B}$ \\
\hline 1 & 53.59 & 17.82 & 18.37 & 0.16 & 2.89 & 0.5 & 0.98 & 5.04 & 0.08 & 0.02 & 0.003 \\
2 & 54.17 & 17.83 & 18.06 & 0.18 & 2.94 & 0.53 & 0.9 & 5.14 & 0.118 & 0.032 & 0.004 \\
3 & 52.5 & 18.35 & 18.42 & 0.35 & 2.96 & 0.57 & 0.97 & 5.32 & 0.1 & 0.03 & 0.004 \\
4 & 54.43 & 17.89 & 16.85 & 0.18 & 2.98 & 0.5 & 0.96 & 5.49 & 0.08 & 0.02 & 0.004 \\
\hline
\end{tabular}

effect of alloy content and heat treatment can thereby also be examined instead of only specimen to specimen differences such as manufacturing discrepancies, test condition differences, measurement errors etc.

\section{Tensile strength and differences in alloy contents}

The ordered specifications have been the same for all batches, a grain size of approximately $10 \mu \mathrm{m}$ (measured by the line interception method), and heat treatment and ageing according to AMS 5663 standard. However, as always, discrepancies from time to time makes it very hard (or maybe close to impossible) to receive exactly the same material output. In Table 3 the alloy content for each batch in the project is shown, where Batch 1 originates from Phase 1 of the project. Some tensile test data were also available in the material certificates, these are seen in Table 4, where it can be noted that for Batch 3 no yield limit was specified at elevated temperature.

\section{Microstructural differences}

When examining the microstructure of the batches, some differences could be seen. Although all batches were heat treated according to the same standard, Batch 1 and Batch 2 contained more $\delta$ phase than Batch 3, see Fig. 11 (white plate-like regions). The $\delta$ phase originates from transformed $\gamma^{\prime \prime}$ phase in the alloy, making it less strong (see the chapter about superalloys). Batch 4 on the other hand has a significantly different microstructure from the others. This is most likely due to the fact that it originates from a turbine disc which has been forged to its final form. Here a significant amount of $\delta$ phase is also visible, which might affect the crack growth results significantly, cf. Paper IX. Differences in microstructure due to heat treatment and manufacturing must therefore be kept in mind when designing against fatigue.

Table 4: Tensile test data for all batches at room temperature (RT) and for the elevated temperature (ET) $650^{\circ} \mathrm{C}$. Data from material certificates.

\begin{tabular}{llllll}
\hline Batch & $\mathrm{R}_{\mathrm{p} 0.2}[\mathrm{MPa}](\mathrm{RT})$ & $\mathrm{R}_{\mathrm{m}}[\mathrm{MPa}](\mathrm{RT})$ & $\mathrm{R}_{\mathrm{p} 0.2[\mathrm{MPa}](\mathrm{ET})}$ & $\mathrm{R}_{\mathrm{m}}[\mathrm{MPa}](\mathrm{ET})$ & Origin \\
\hline 1 & 1110 & 1420 & 955 & 1143 & Bar 1.0" \\
2 & 1084 & 1403 & 955 & 1193 & Bar 1.25" \\
3 & 1269 & 1448 & - & - & Bar 1.0" \\
4 & 1190 & 1484 & 1006 & 1192 & Turbine disc \\
\hline
\end{tabular}




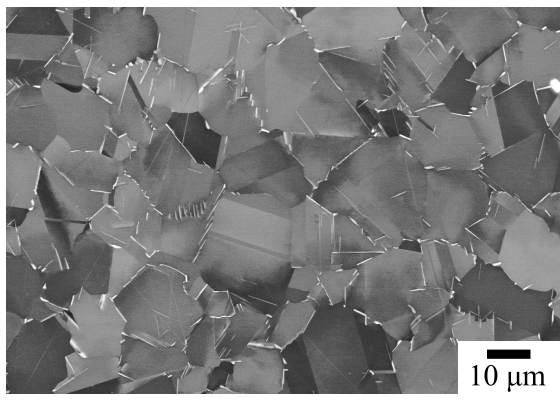

(a)

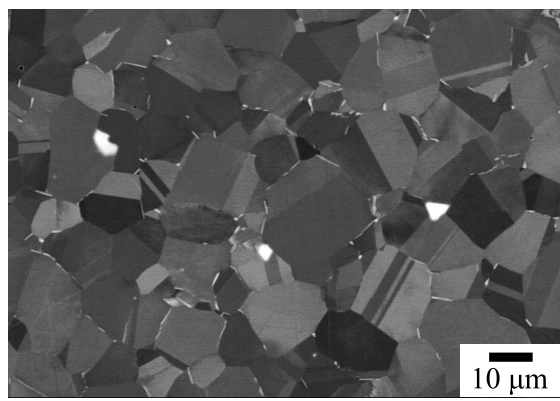

(c)

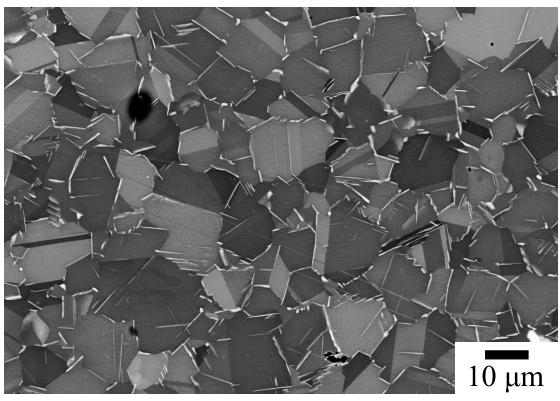

(b)

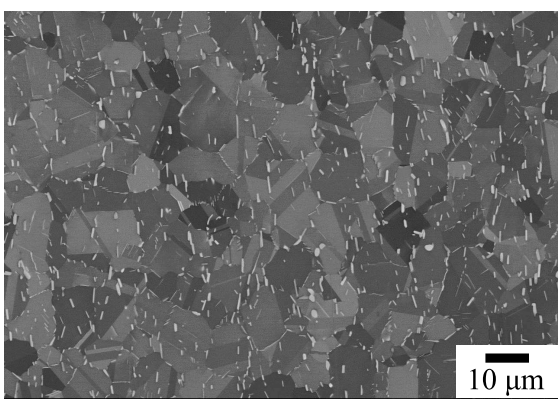

(d)

Figure 11: Microstructure for the batches used in the project; (a) Batch 1, (b) Batch 2, (c) Batch 3 and (d) Batch 4. Batches 2 and 3 discussed in Paper VIII.

\section{Effect on crack growth rates}

To clarify which batch was used for a certain mechanical experiment becomes important for comparison purposes and for further research and industrial implementation of the model. In Tables 5 and 6, a summary of all experiments and their respective batch are given, where a note is also given if the test is originates from Phase 1 of the TURBO POWER programme.

In the work reported in this dissertation some material parameters were derived, see the previous sections. A comparison is provided in Table 7 to give an overview of the parameters and how they relate to each material batch. From this it can be seen that if an industrial application study is going to be undertaken, a mean value or combined optimisation process would be of use, cf. Paper VI where 2 batches were used together, or Paper VII where several tests from the same batch were used. Note that in Paper IV, Paper VI, Paper VII and Paper X the parameters for the cyclic growth are closure corrected, while in Paper II and Paper III only $R=0.05$ was used.

An important question remains, how do the batch differences affect the crack growth rate? In Table 7 it can clearly be seen that the model parameters have been affected. To give a more explicit view of the impact on the growth properties, some test have been selected to represent the differences. In Fig. 12(a) one BL $R=0.05$ 
Table 5: Tests and their respective batch, appearance in each paper $(\mathbf{I}-\mathbf{X})$ is marked by " $\mathrm{X}$ ”, “1” indicate that the test was performed within Phase 1 of the TURBO POWER programme.

\begin{tabular}{|c|c|c|c|c|c|c|c|c|c|c|c|c|c|}
\hline Test & Batch & Temp. $\left[{ }^{\circ} \mathrm{C}\right]$ & Test type & I & II & III & IV & V & VI & VII & VIII & IX & $\mathrm{X}$ \\
\hline $01^{1}$ & 1 & 550 & $\mathrm{BL} R=0.6$ & - & - & - & $\mathrm{x}$ & - & $\mathrm{x}$ & - & - & - & - \\
\hline $02^{1}$ & 1 & 550 & $\mathrm{BL} R=0.05$ & - & - & - & $\mathrm{x}$ & - & - & - & - & - & - \\
\hline 03 & 2 & 550 & BL $R=0.05$ & $\mathrm{x}$ & - & - & - & $\mathrm{x}$ & - & - & $\mathrm{x}$ & - & - \\
\hline 04 & 3 & 550 & BL $R=0.05$ & - & - & - & - & - & $\mathrm{x}$ & - & $\mathrm{x}$ & - & $\mathrm{x}$ \\
\hline $05^{1}$ & 1 & 550 & Sustained load & $\mathrm{x}$ & $\mathrm{x}$ & $\mathrm{x}$ & - & - & - & - & - & - & - \\
\hline $06^{1}$ & 1 & 550 & Sustained load & - & $\mathrm{x}$ & $\mathrm{x}$ & - & - & - & - & - & - & - \\
\hline 07 & 2 & 550 & Sustained load & - & - & - & - & - & - & - & $\mathrm{x}$ & - & - \\
\hline 08 & 3 & 550 & Sustained load & - & - & - & - & $\mathrm{x}$ & - & - & $\mathrm{x}$ & - & - \\
\hline 09 & 3 & 550 & Sustained load & - & - & - & - & $\mathrm{x}$ & $\mathrm{x}$ & $\mathrm{x}$ & $\mathrm{x}$ & - & $\mathrm{x}$ \\
\hline 10 & 3 & 550 & Sustained load & - & - & - & - & - & - & $\mathrm{x}$ & $\mathrm{x}$ & - & $\mathrm{x}$ \\
\hline $11^{1}$ & 1 & 650 & Sustained load & $\mathrm{x}$ & - & $\mathrm{x}$ & - & - & - & - & - & - & - \\
\hline $12^{1}$ & 1 & 550 & Dwell 90s & $\mathrm{x}$ & - & $\mathrm{x}$ & - & - & - & - & - & - & - \\
\hline $13^{1}$ & 1 & 550 & Dwell 90s & - & - & $\mathrm{x}$ & - & - & - & - & - & - & - \\
\hline $14^{1}$ & 1 & 650 & Dwell 90s & $\mathrm{x}$ & - & $\mathrm{x}$ & - & - & - & - & - & - & - \\
\hline $15^{1}$ & 1 & 450 & Dwell 2160s & - & - & - & - & - & - & - & - & $\mathrm{x}$ & - \\
\hline $16^{1}$ & 1 & 550 & Dwell 2160s & $\mathrm{x}$ & $\mathrm{x}$ & $\mathrm{x}$ & - & - & - & - & - & - & - \\
\hline 17 & 2 & 550 & Dwell 2160s & - & - & $\mathrm{x}$ & - & - & - & - & $\mathrm{x}$ & $\mathrm{x}$ & - \\
\hline 18 & 3 & 550 & Dwell 2160s & - & - & - & - & - & - & - & $\mathrm{x}$ & - & $\mathrm{x}$ \\
\hline $19^{1}$ & 1 & 650 & Dwell 2160s & - & - & $\mathrm{x}$ & - & - & - & - & - & $\mathrm{x}$ & - \\
\hline $20^{1}$ & 1 & 650 & Dwell 2160s & - & - & $\mathrm{x}$ & - & - & - & - & - & - & - \\
\hline $21^{1}$ & 1 & 550 & Dwell 21600s & $\mathrm{x}$ & $\mathrm{x}$ & $\mathrm{x}$ & - & - & - & - & - & - & - \\
\hline 22 & 2 & 550 & Dwell 2160s OL 2.5\% & $\mathrm{x}$ & - & - & - & - & - & - & $\mathrm{x}$ & - & - \\
\hline 23 & 3 & 550 & Dwell 2160s OL 2.5\% & - & - & - & - & - & - & - & $\mathrm{x}$ & - & - \\
\hline 24 & 2 & 550 & Dwell 2160s OL 5\% & $\mathrm{x}$ & - & - & - & - & - & - & $\mathrm{x}$ & - & - \\
\hline 25 & 3 & 550 & Dwell 2160s OL 5\% & - & - & - & - & - & - & - & $\mathrm{x}$ & - & - \\
\hline 26 & 2 & 550 & Dwell 2160s OL 15\% & $\mathrm{x}$ & - & - & - & - & - & - & $\mathrm{x}$ & - & - \\
\hline 27 & 3 & 550 & Dwell 2160s OL 15\% & - & - & - & - & - & - & - & $\mathrm{x}$ & - & - \\
\hline $28^{1}$ & 1 & 550 & Block 90 s & - & $\mathrm{x}$ & $\mathrm{x}$ & - & - & - & - & - & - & - \\
\hline $29^{1}$ & 1 & 650 & Block 90s & - & - & $\mathrm{x}$ & - & - & - & - & - & - & - \\
\hline $30^{1}$ & 1 & 550 & Block 180s & - & - & $\mathrm{x}$ & - & - & - & - & - & - & - \\
\hline $31^{1}$ & 1 & 550 & Block 2160s & - & - & $\mathrm{x}$ & - & - & - & - & - & - & - \\
\hline $32^{1}$ & 1 & 550 & Block 21600s & - & $\mathrm{x}$ & $\mathrm{x}$ & - & - & - & - & - & - & - \\
\hline
\end{tabular}

test is seen from each batch, in Fig. 12(b) the sustained load tests (or the sustained load part of the mixed test) from each batch are seen, and in Fig. 12(c) one $2160 \mathrm{~s}$ test from each batch are seen. Every test in these figures are for $550^{\circ} \mathrm{C}$ for comparison purposes. Clearly, for the cyclic tests, little or no difference between the batches is seen, thus indicating that the microstructure has little or no influence on transgranular fracture. On the other hand for the tests with dwell time, a remarkable difference is seen, which shows how large impact the microstructure has on the crack growth rate. Consequently, scatter has to be taken into consideration in order to predict accurate results when dwell times are present. This is further discussed in Paper VIII, where the impact of overloads on dwell times are discussed with respect to Batch 2 and Batch 3.

It is of importance to show how the model performs compared to the superposition model in Eq. (3) (which has also been used for comparison purposes in Paper IV and Paper VII) since scatter is clearly of significance. As a result, all dwell time tests (except 
Table 6: Tests and their respective batch, appearance in each paper $(\mathbf{I}-\mathbf{X})$ is marked by " $\mathrm{x}$ ”, “1” indicate that the test was performed within Phase 1 of the TURBO POWER programme.

\begin{tabular}{|c|c|c|c|c|c|c|c|c|c|c|c|c|c|}
\hline Test & Batch & Temp. $\left[{ }^{\circ} \mathrm{C}\right]$ & Test type & I & II & III & IV & $\mathrm{V}$ & VI & VII & VIII & IX & $\mathrm{X}$ \\
\hline 33 & 2 & 550 & Block OL $2.5 \%$ & - & - & - & - & - & - & - & $\mathrm{x}$ & - & - \\
\hline 34 & 3 & 550 & Block OL 10\% & - & - & - & - & - & - & - & $\mathrm{x}$ & - & - \\
\hline 35 & 3 & 550 & Block OL 10\% & - & - & - & - & - & - & - & $\mathrm{x}$ & - & - \\
\hline 36 & 2 & 550 & Mixed & - & - & $\mathrm{x}$ & $\mathrm{x}$ & $\mathrm{x}$ & $\mathrm{x}$ & - & $\mathrm{x}$ & $\mathrm{x}$ & - \\
\hline 37 & 2 & 550 & Mixed & - & - & - & - & - & - & - & $\mathrm{x}$ & - & - \\
\hline 38 & 3 & 550 & Mixed & - & - & - & - & - & - & $\mathrm{x}$ & $\mathrm{x}$ & - & $\mathrm{x}$ \\
\hline 39 & 1 & 600 & Mixed & - & - & $\mathrm{x}$ & - & - & - & - & - & $\mathrm{x}$ & - \\
\hline 40 & 1 & 650 & Mixed & - & - & $\mathrm{x}$ & - & - & - & - & - & $\mathrm{x}$ & - \\
\hline 41 & 2 & 550 & Spectrum & - & - & - & $\mathrm{x}$ & - & - & - & - & - & - \\
\hline 42 & 2 & 550 & Spectrum & - & - & $\mathrm{x}$ & - & - & - & - & - & - & - \\
\hline 43 & 3 & 550 & Spectrum & - & - & - & - & - & - & $\mathrm{x}$ & - & - & - \\
\hline 44 & 3 & 550 & Spectrum & - & - & - & - & - & - & $\mathrm{x}$ & - & - & - \\
\hline 45 & 3 & 550 & Spectrum & - & - & - & - & - & - & $\mathrm{x}$ & - & - & - \\
\hline 46 & 1 & 600 & Spectrum & - & - & $\mathrm{x}$ & - & - & - & - & - & - & - \\
\hline 47 & 1 & 600 & Spectrum & - & - & $\mathrm{x}$ & - & - & - & - & - & - & - \\
\hline 48 & 3 & 550 & HCF dwell & - & - & - & - & - & - & - & - & - & $\mathrm{x}$ \\
\hline 49 & 3 & 550 & HCF dwell & - & - & - & - & - & - & - & - & - & $\mathrm{x}$ \\
\hline 50 & 3 & 550 & HCF dwell 2160s & - & - & - & - & - & - & - & - & - & $\mathrm{x}$ \\
\hline 51 & 3 & 550 & HCF mixed & - & - & - & - & - & - & - & - & - & $\mathrm{x}$ \\
\hline 52 & 3 & 550 & HCF mixed & - & - & - & - & - & - & - & - & - & $\mathrm{x}$ \\
\hline $53^{1}$ & 4 & $50-550$ & TMF dwell Os & - & - & - & - & - & - & - & - & $\mathrm{x}$ & - \\
\hline $54^{1}$ & 4 & $50-550$ & TMF dwell Os & - & - & - & - & - & - & - & - & $\mathrm{x}$ & - \\
\hline $55^{1}$ & 4 & $50-550$ & TMF dwell Os & - & - & - & - & - & - & - & - & $\mathrm{x}$ & - \\
\hline $56^{1}$ & 4 & $50-550$ & TMF dwell 300s & - & - & - & - & - & - & - & - & $\mathrm{x}$ & - \\
\hline $57^{1}$ & 4 & $50-550$ & TMF dwell 300s & - & - & - & - & - & - & - & - & $\mathrm{x}$ & - \\
\hline $58^{1}$ & 4 & $50-550$ & TMF dwell 300s & - & - & - & - & - & - & - & - & $\mathrm{x}$ & - \\
\hline $59^{1}$ & 4 & $50-550$ & TMF dwell 300s & - & - & - & - & - & - & - & - & $\mathrm{x}$ & - \\
\hline $60^{1}$ & 4 & $50-550$ & TMF dwell 300s & - & - & - & - & - & - & - & - & $\mathrm{x}$ & - \\
\hline $61^{1}$ & 4 & $50-550$ & TMF dwell Os & - & - & - & - & - & - & - & - & $\mathrm{x}$ & - \\
\hline $62^{1}$ & 4 & $50-550$ & TMF dwell 21600s & - & - & - & - & - & - & - & - & $\mathrm{x}$ & - \\
\hline $63^{1}$ & 4 & $50-550$ & TMF dwell os & - & - & - & - & - & - & - & - & $\mathrm{x}$ & - \\
\hline $64^{1}$ & 4 & $50-550$ & TMF dwell 21600s & - & - & - & - & - & - & - & - & $\mathrm{x}$ & - \\
\hline
\end{tabular}

the ones with overload) in Tables 5 and 6 have been simulated with the parameters in Table 7 using the developed model, and compared to the respective simulation using the superposition model in Eq. (3). The result of this is seen in Fig. 13, where both a log-normal probability plot is seen (see also Paper III) and a comparison of all tests how they perform to each other with the two different models. From this it can be seen that the developed model centres around the ratio 1 (same simulation as experimental value) and that the superposition model is conservative (as expected). Some non-conservative predictions are also seen for the history dependent model which has to be taken into account when choosing safety factor.

A final interesting aspect to consider when discussing scatter is the length of the stabilised damaged zone, $D_{\max }$, which is seen to be constant for a specific temperature. Results from measurements of it have been shown to be very constant from batch to batch, by which it can be concluded that the small differences in alloy content and heat 
Table 7: Model parameters used in all papers in this dissertation, note that in Paper II an early development of the model was used and that in Paper IX the parameters are functions of temperature, units in $\mathrm{MPa}, \mathrm{MPa} \sqrt{\mathrm{m}}, \mathrm{m} / \mathrm{s}$ and $\mathrm{m} /$ cycle; $D_{\max }$ in $\mathrm{mm}$.

\begin{tabular}{lllllllllll}
\hline Paper & Temp $\left[{ }^{\circ} \mathrm{C}\right]$ & Batch & $C_{\mathrm{ot}_{\mathrm{t}}}$ & $n_{\mathrm{t}}$ & $C_{\mathrm{c}}$ & $n_{\mathrm{c}}$ & $B_{\mathrm{t}}$ & $A_{\mathrm{c}}$ & $B_{\mathrm{c}}$ & $D_{\max }$ \\
\hline II & 550 & 1 & $5.76 \times 10^{-15}$ & 4.57 & $1.26 \times 10^{-10}$ & 2.39 & 1.62 & 823 & 2.92 & 0.5 \\
III & 550 & 1 & $3.90 \times 10^{-13}$ & 3.3 & $1.80 \times 10^{-10}$ & 2.3 & 0.71 & 303 & 2.70 & 0.5 \\
III & 550 & 2 & $3.90 \times 10^{-13}$ & 3.3 & $1.80 \times 10^{-10}$ & 2.3 & 0.35 & 303 & 2.70 & 0.5 \\
III & 600 & 1 & $9.10 \times 10^{-12}$ & 3.0 & $1.50 \times 10^{-10}$ & 2.5 & 0.42 & 283 & 3.00 & 0.7 \\
III & 650 & 1 & $6.00 \times 10^{-12}$ & 3.7 & $1.20 \times 10^{-11}$ & 3.5 & 0.51 & 180 & 3.00 & 0.8 \\
IV & 550 & 2 & $3.90 \times 10^{-13}$ & 3.3 & $3.30 \times 10^{-10}$ & 2.3 & 0.35 & 331 & 2.70 & 0.5 \\
VI & 550 & $2 \& 3$ & $2.60 \times 10^{-13}$ & 3.3 & $3.30 \times 10^{-10}$ & 2.3 & 1.45 & 331 & 2.70 & 0.5 \\
VII & 550 & 3 & $3.60 \times 10^{-14}$ & 3.8 & $3.00 \times 10^{-10}$ & 2.3 & 2.50 & 338 & 2.70 & 0.5 \\
IX & 550 & $1 \& 2$ & $f_{1}(T)$ & $f_{2}(T)$ & - & - & $f_{3}(T)$ & - & - & $f_{4}(T)$ \\
X & 550 & 3 & $3.60 \times 10^{-14}$ & 3.8 & $3.00 \times 10^{-10}$ & 2.3 & 4.8 & 215 & 2.10 & 0.5 \\
\hline
\end{tabular}

treatment do not seem to have any influence on this parameter. What on the other hand can be seen is a difference in the transient slope before reaching the stabilised dwell time crack growth, see Fig. 12(b). Here it can be seen that Batch 3 has a much higher initial slope than Batch 1 and Batch 2, probably because of different time needed for the crack to propagate through the damaged zone in the different batches. Further discussion regarding the transients on the time-dependent crack growth rates can be found in Paper VIII.

\subsection{Crack growth constraint}

In crack growth testing it has been seen that a significant difference in crack growth rate is gained for different parts of a test specimen, both during rapid cyclic growth and during dwell times, cf. Paper V. Studies of this has been conducted, and it has been seen that the growth rate can be closely related to the constraint level, i.e. the triaxial stress state at the crack front, $\eta=\left(\sigma_{x x}+\sigma_{y y}+\sigma_{z z}\right) / 3 \sigma_{\mathrm{e}}^{\mathrm{vM}}$, which of course also affects the crack shape evolution, see e.g. [16]. Different parameters have been used to describe this and take it into account into growth laws, cf. [15]. Other methods for calculating the plane stress/strain state has also been used, cf. Paper VI for an overview, e.g. deriving the stress at the crack tip (requires high mesh density). With new methods e.g. three-dimensional crack growth simulations, there is a need for being able to characterise the stress state without requiring a high amount of computational recourses.

It has been seen from fracture surfaces that not only the cyclic crack growth but also the sustained load affects the shape of the crack front, which in contrast to crack closure for cyclic growth, can be related to the supply of embrittling elements (e.g. oxygen). The damaged zone should therefore be of different length when examining test specimen types with different triaxial stress states. Here only one specimen type has been used which has given only one length measure of the damaged zone. Other test specimen types, e.g. CT specimens with a through crack, could show a different stabilised damaged zone length. This will open up for further studies of how to 


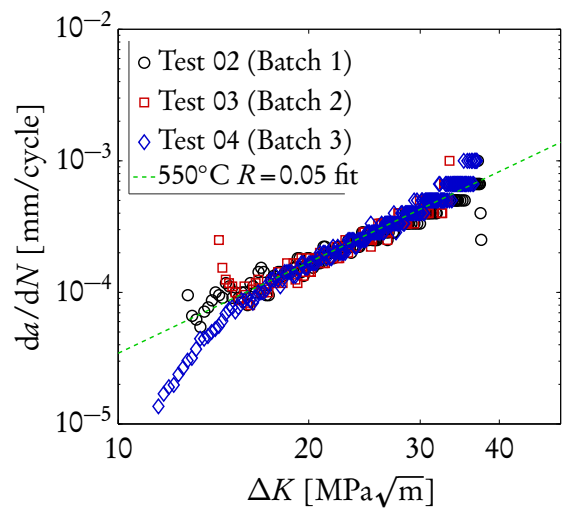

(a)

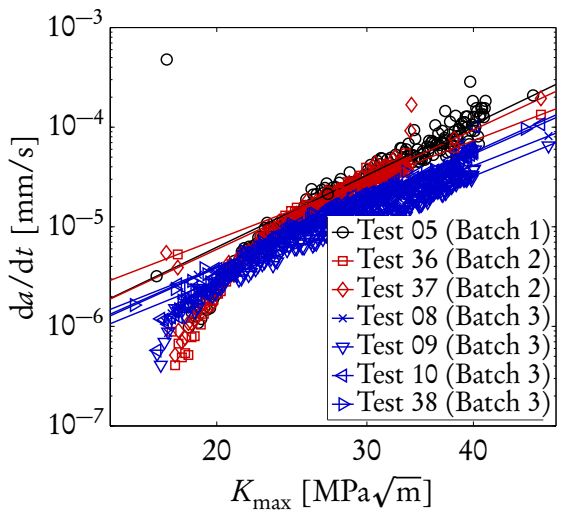

(b)

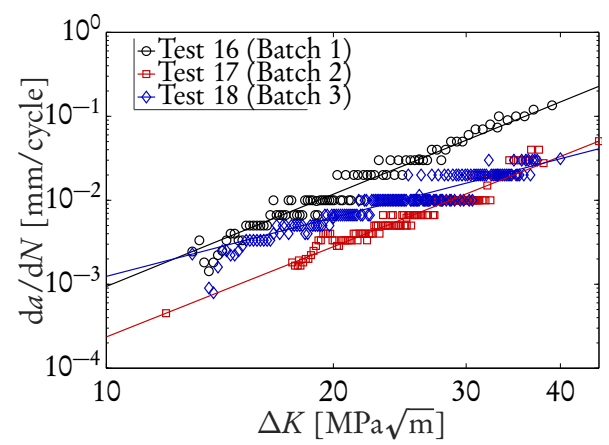

(c)

Figure 12: Crack growth rate for the different batches at $550^{\circ} \mathrm{C}$. (a) Cyclic loading, (b) sustained load and (c) $2160 \mathrm{~s}$ dwell time.

calibrate the model with respect to what plane stress/strain relation is present in the actual component.

For all tests, as mentioned before, a pre-defined calibration curve was used for evaluation of crack length and related growth rates. As it was based on a cyclic test with $R_{\sigma}=0.05$, some differences will of course be received for other $R$ ratios and for cases with dwell times. Dwell time tests have in particular been seen to exhibit some major crack tunnelling compared to cyclic crack growth tests, which makes it important to investigate how much the evaluated crack length and damaged zone length differ compared to a perfect semi-circular shape. This has been studied in Paper $\mathrm{V}$ where it was shown on fracture surfaces how the crack length evaluation differs from PD, and in Paper VI where it was shown how the shape of the damaged zone can be predicted by the use of constraint parameters. It may from these studies be concluded that assuming a semi-circular crack shape gives the correct crack length, but information of the crack front shape is lost. To improve the evaluation of the 


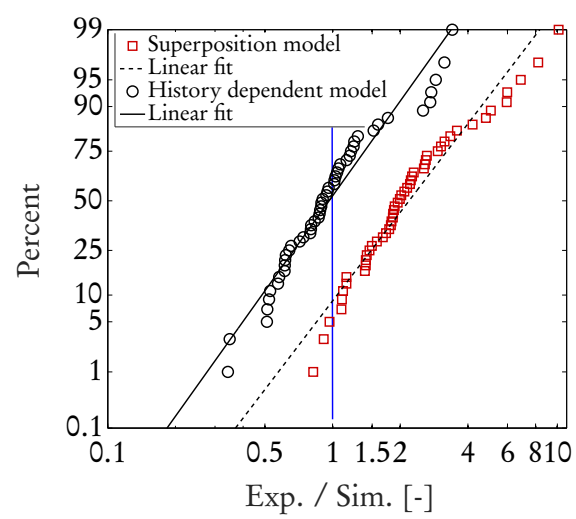

(a)

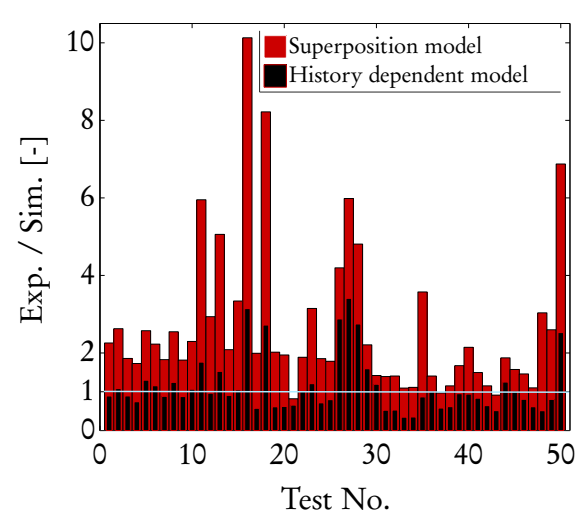

(b)

Figure 13: Experimental and simulation ratio for all dwell time tests simulated in Paper I - X. (a) Log-normal probability plot and (b) comparison of all tests.

crack shape evolution, some complementary method should be used, e.g. studying of the crack length on the surface of the test specimen. As an example, Fig. 14 shows a schematic fracture surface with the evaluated crack length as a semi-circle and the actual crack length seen on the post-mortem fracture surface. It can be seen that the evaluated crack shape from PD differs locally from the actual test (cf. Paper V). The difference in crack length between the two (ideal and actual shape) differs $1 \%$ to each other (translated area of the fracture surface into crack length) for the first sustained load test in Paper V, which can be regarded as only minor differences.

An interesting problem which arises due to the influence of triaxial stress state is how to take care of the transition areas, when the crack grows through a structure. How to take care of this for cyclic loading can e.g. be found in NASGRO [14] where the $\alpha$-value in Newmans crack closure law can be modified. The value of $\alpha$ is defined as the ratio of the normal stress to the crack plane $\left(\sigma_{y y}\right)$ and the flow stress $\left(\sigma_{0}\right)$ which is the average of the yield and ultimate tensile strength, i.e. $\alpha=\sigma_{y y} / \sigma_{0}$ [57]. For dwell times on the other hand no such entity has been found in the literature. To handle this, one could e.g. scale the time dependent crack growth parameters with the cyclic

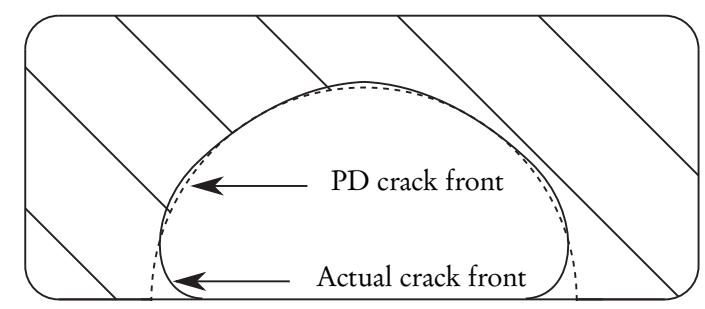

Figure 14: Schematic fracture surface with the actual crack front by post-mortem inspection and the crack front by the 1D PD evaluation. Based on Paper V. 
$\alpha$ value as in Paper VI. However, there is a need for studying this topic further. In Paper IX a corner crack developing into a through crack was analysed, where the same growth parameters were used independent of geometrical constraints, here the growth rate could have been scaled to account for triaxiality if the correct data had been available. 



\section{Review of appended papers}

The appended papers in this dissertation are presented in their chronological order of production, in Fig. 15 the connection between the papers are presented.

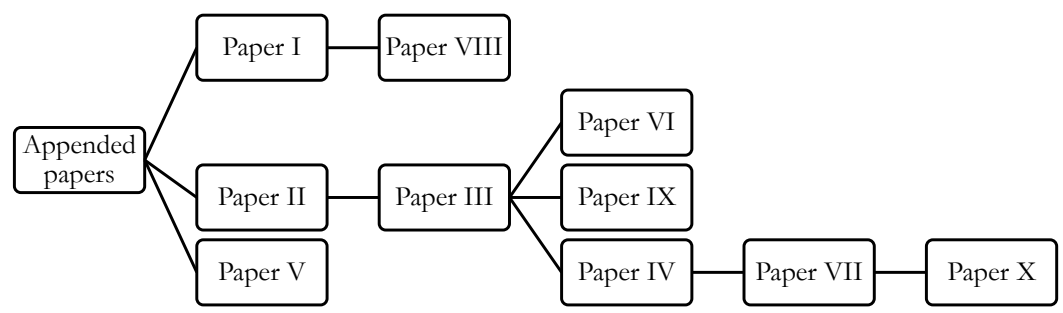

Figure 15: Connection between the appended papers.

\section{Paper I}

High temperature fatigue crack growth behaviour of Inconel 718 under hold time and overload conditions

The fatigue crack propagation behaviour of Inconel 718 with and without dwell times has been studied for $550^{\circ} \mathrm{C}$ and $650^{\circ} \mathrm{C}$. In addition to this, sustained load tests with and without initial overloads have been studied for $550^{\circ} \mathrm{C}$. The initial overloads had a major influence on the crack propagation rate, and the cause of this was believed to be the stress state in front of the crack tip. To investigate the cause, a simple 2D FE model was set up to show how the stress field is affected by an overload. Further, a simple fatigue crack growth model was developed to cope with the overload effect. The model was based on the concept of a damaged zone in front of the crack tip caused by the sustained load, which was also confirmed by a brief microscopy study of the crack front. 


\section{Paper II}

Modelling of high temperature fatigue crack growth in Inconel 718 under hold time conditions

The paper focuses on the modelling of crack growth during sustained load and interaction with rapid load reversals at a temperature of $550^{\circ} \mathrm{C}$, with focus on creating a physically motivated phenomenological model. By applying scale factors for the build-up of the damaged zone during hold times, and subsequent consumption during rapidly applied load reversals a history dependent physically motivated model was created. The model was successfully applied for long dwell times and a variety of different load sequences.

\section{Paper III}

A load history dependent model for fatigue crack propagation in Inconel 718 under hold time conditions

Further development of the dwell time crack growth model which was presented in Paper II was conducted. The model was extended by a description of the sustained load behaviour which includes an additional term to handle the incubation time commonly seen during the initial part of a dwell time test. As a result, the modelling concept is now able to handle both short and long dwell times. The incubation time term serves as a description of how the damaged zone is initially built up. However, the model contains the same number of fitting parameters as the model in the previous paper. In addition, an efficient calibration method was developed for parameter identification, which was successfully applied for 550,600 and $650^{\circ} \mathrm{C}$. With the new modelling concept and calibrated parameters, a total of 22 different tests were investigated. The results were used for statistical evaluation, which showed that the model gives a reasonable scatter factor for a probability of failure of $0.1 \%$.

\section{Paper IV}

Modelling of fatigue crack growth in Inconel 718 under hold time conditions - application to a flight spectrum

To validate the model under more application-like conditions a flight component spectrum was used for this study. The spectrum was run under isothermal conditions at $550^{\circ} \mathrm{C}$ and involved a variety of different load ratios and dwell times. To process the spectrum information, a manual evaluation method was used to identify individual cyclic parts and dwell time parts. In order to simulate this loading situation, the model developed in the previous paper was extended by the crack closure routine by Newman [15]. The results showed good correlation to test data, which also confirmed that the damaged zone concept can be used for predicting life of actual components. To further 
show the benefits of the model a comparison to a non-history-dependent model was made on the same spectrum, where the latter not surprisingly underpredicts the time to final crack length.

\section{Paper V}

Crack length evaluation for cyclic and sustained loading at high temperature using potential drop

With the increased knowledge of dwell times and how they affect the crack growth rate, a study was performed on how to evaluate sustained load tests with respect to what is seen on the actual fracture surface and how this relates to the crack growth rate. Three different test types were evaluated with three different evaluation methods, which showed non-negligible differences between each method on the resulting crack propagation rate values. Scanning Electron Microscopy (SEM) was used on some of the fracture surfaces to identify the cause for the discrepancy, which was found to be linked to the damaged zone discussed in previous papers. The conclusion which can be drawn from this paper is that for the most accurate results regarding crack growth evaluations one should consider the damaged zone as a length added to the crack length evaluated by potential drop with a calibration curve derived from a cyclic test. In the long term use, one can use these results to better understand how to incorporate history dependence into crack propagation models with the damaged zone as a control parameter.

\section{Paper VI}

\section{Three-dimensional crack growth modelling of a Ni-based superalloy at elevated temperature and sustained loading}

A common problem with fatigue crack growth analyses is constraint dependence, which can affect the growth rate significantly. Also the behaviour under dwell times has been shown to be sensitive to the state of plane strain/stress that is present along the crack front, which affects the crack shape. Modelling of such constraint effects have traditionally been handled by heavy numerical FE simulations in order to describe e.g. the triaxial stress state. How to handle such issues and the related interaction between sustained and cyclic load in an generalised 3D context have been studied in this paper. The modelling concept has been based on the damaged zone concept as previously developed for $1 \mathrm{D}$, which is here extended to 3D. An efficient concept is gained by using numerical simplifications and distribution of $1 \mathrm{D}$ results to a general 3D situation. Simulations and associated projections to fracture surfaces show accurate results for cyclic loads with two different load ratios, sustained load, as well as a mix of both. 


\section{Paper VII}

Modelling of crack growth with dwell time for aero engine spectra loadings in a Ni-based superalloy

The focus on real engine spectra has always been an important factor for validating the developed modelling concept in the project. In this paper the model in Paper IV has been extended to handle arbitrary engine loadings and to provide for an automatic identification process for loading cycles. By introducing criteria of which damage mode should be active at a certain situation, crack growth for a spectrum can now easily be predicted with minimum user input. Three engine spectra have been predicted with respect to the number of load sequences; one with no dwell times, one with sustained load between each load reversal and finally one spectrum with slow load ramps as seen at e.g. engine start-up and shut down. All simulations show reasonably good agreement with experimental results.

\section{Paper VIII}

Scatter in dwell time cracking for a Ni-based superalloy in combination with overloads

Looking back on Paper I one can see a heavy influence of overloads prior to dwell times. However, as scatter can have a large influence on results regarding fatigue one can very seldom base all conclusions on 1 batch of material. In this paper 2 material batches were investigated for 20 different tests, based on material with the same grain size, heat treatment standard etc., but with surprisingly different tensile and rupture strengths. Also a different dwell time behaviour was observed, where the batch with the lower strength showed a remarkable overload effect which significantly decreased the crack growth rate, while for the same load level the other showed no such effect, most likely due to crack blunting in the former which reduced the crack growth level. As a result of this study, it is recommended not to consider overloads in the design process of a gas turbine unless substantial material data are available.

\section{Paper IX}

Thermo-mechanical fatigue crack growth modelling in a Ni-based superalloy subjected to sustained load

The majority of all gas turbine components experience a varying temperature over time, e.g. during start up, shut down and variations in engine thrust. Also, most critical engine components exhibit the highest load levels at stress concentrations, e.g. at holes and notches, which can greatly affect the crack growth rate. One can also note that most components under heating and cooling are subjected to strain control rather than stress control, which is another important factor that comes into play. A study 
regarding these issues was therefore initiated where results from a previous study were used (see [53]). In that work, notched test specimens were tested under strain control and the temperature range of $50^{\circ} \mathrm{C}-550^{\circ} \mathrm{C}$ with $1^{\circ} \mathrm{C} / \mathrm{s}$ heating/cooling rate, creating engine like conditions. Surface crack specimens were also used from Paper III for calibration purposes. With the isothermal tests, the model discussed in Paper III and Paper IV was further developed and used to predict the TMF tests. Satisfying results are gained within reasonable scatter level for number of cycles to failure, considering the different constraint levels for the different test specimens, different batches etc. The paper also highlights the importance of being able to use data for one test specimen type for predicting life on a completely other geometry.

\section{Paper X}

Impact of high cycle fatigue on dwell time crack growth in a Ni-based superalloy

In many situations, vibrations of different kind may have significant effect on the crack propagation behaviour. Such high cycle fatigue (HCF) loads/flutter can be a source of failure in their own, but have seldom been investigated as a superimposed load on dwell time loadings. How the two load modes interact with each other and how to model such behaviour was therefore investigated in this paper. Several tests involving different HCF loads were performed, and a modelling work based on the damaged zone approach in previous papers was conducted. In addition to this, the fracture paths were studied using SEM in order to investigate how engine HCF loads/flutter affect the dwell time cracking behaviour. The modelling work in combination with the experimental results and microscopy study contributes to raise the Technological Readiness Level (TRL) in order to be able to incorporate the damaged zone model into an industrially applicable design process. 



\section{Discussion and conclusions}

More extreme and different operating conditions for gas turbines have driven the development of life prediction methodologies towards increased accuracy and reliability. In the work presented in this dissertation, a further step in this direction has been taken, aiming at a modelling level suitable for use in most situations. The major goal has been a physically motivated model which can be incorporated in the design process, and used in an everyday situation by stress engineers.

To reach the goals set up by the TURBO POWER programme, a number of investigations were initiated. First, in order to improve efficiency for gas turbines and to improve operation economy, one needs to be able to run the aero engines for longer periods of time, and be able to start and stop stationary turbines more often than today as the amount of solar and wind power increases. To achieve this, more accurate model predictions than are available today are needed. As a part in this process, a number of papers were written on improved modelling capabilities. By studying experimental data a first model concept was initiated, based on the build-up and subsequent consumption of the damaged zone. This was first realised in Paper II were a model for describing very long dwell times was presented. The ability to describe the transients seen in the $\mathrm{d} a / \mathrm{d} t$ data, as seen in e.g. the $21600 \mathrm{~s}$ test in the same paper, was the first necessary step in order to describe the interaction between rapid cyclic load and dwell times. The approach differs from the other models found in the literature by the fact that it takes into account the damaged zone length in describing the crack growth rate itself.

The initial modelling achievements in Paper II gave motivation to continue by the same approach in Paper III. In this paper, where 2 batches were studied (1 previous from Paper II and 1 new), it was concluded that the second material batch behaved a little bit differently from the first one in the sense that more time was needed before the crack could re-orientate itself through the grain boundaries. This phenomenon had also been seen in many other articles, which called for some development. With the newly developed model it was possible also to handle short dwell times down to $90 \mathrm{~s}$ (shortest one tested), thus improving the usefulness of the model even further. Further, as the model parameters were now stretching to a non-negligible number, it called for a need to develop an efficient calibration procedure.

Following these 2 studies, a number of other studies were conducted in order to give the model higher Technological Readiness Level (TRL) for incorporation in industrial use. Paper IV and Paper VII focused on validating the model for a number of load spectra seen in aero engines, and reasonable agreement to experimental findings was achieved. Here some shortcoming was found when dwell times were given a non-zero time derivative, simulating slow start-up of the turbine. 
To increase the TRL level even more, 3 separate studies were performed; the first one focusing on three-dimensional crack growth (Paper VI), the second one concerning the influence of temperature variations and the ability to transfer crack growth results from one geometry to an other (Paper IX), and the third one concerning the effect of vibrations on dwell time effects (Paper $\mathbf{X}$ ). All three studies showed the importance of being able to have a modelling concept modular enough for extension into areas not being thought of in the early stages in a conceptual development stage. Threedimensional crack growth will perhaps be the most dominating improvement for increased TRL (especially as computational recourses increase). One should however not disregard methods involving traditional design with elementary cases, as these are superior in their simulation efficiency.

Apart from these modelling improvements some other studies were conducted. In Paper V it was studied how to conduct experimental evaluation of dwell time tests and how this situation differs from evaluation where the damaged zone is absent. If conducting evaluation with no damage zone in mind, an increase in crack growth rate also appears, which cannot be physically explained. Consequently, dwell time tests need to be evaluated with care, especially if they are going to be used for gas turbine design where high costs are related to design faults.

The influence of overloads has also been investigated, although not incorporated into the modelling paradigm. This was investigated in Paper I and Paper VIII, respectively. The impact of overloads is of particular interest to a gas turbine manufacturer as the predicted life can be increased substantially, compared to a more conservative design approach. It was found that the resulting crack growth rate was closely related to the ability for blunting to occur. It was also found that material scatter makes it difficult to foresee the effect, and that it at this stage is not advisable to take overloads into account.

Regarding the second part of the TURBO POWER programme goals, the use of new type of fuels and lowering of emissions, i.e. especially the use of renewable fuels, one needs to understand how the metals react to new environments. As understood, this has not been the absolute focus in this work. However, with the physical observations and the chosen modelling approach one should in theory only have to perform similar tests in other operating environments, with additional embrittling elements such as salt or sulphur. Investigating such conditions should be of interest to any gas turbine manufacturer with the introduction of new fuels or the use of gas turbines in different climates. Compare, for instance, desert-sea-arctic differences. 


\section{Outlook}

Modelling and experimental work concerning dwell time crack growth have given many valuable insights, which can be further used for industrial and academic purposes. Although much work has already been completed some major parts still exist. Important aspects which need to be covered are,

- how to incorporate triaxiality into the model in a way that is applicable also from an industrial point of view

- how to apply the developed model on other alloy combinations where some might be more sensitive to dwell times

- how the dwell time crack growth is influenced by grain size and heat treatment needs to be covered in order to apply the model on welded parts of a structure.

In addition, slowly applied load ramps need to be investigated in more depth for correct characterisation of the dwell time cracking and model development. Consequently, the model which has been developed in this work still requires substantial input before it can be considered to be complete.

To apply the model in an industrial context has been a frequently mentioned topic throughout this dissertation. Material scatter should therefore be of major importance as it can have heavy influence on dwell time properties. However, such testing is both costly and time-consuming. In the work presented here, only a few number of batches have been tested, and many more are required to give reliable parameters for use at all time. Such an issue cannot be disregarded.

A final critical aspect should also be mentioned, namely how a model representing a case of perfect isotropy behaves in a more complex geometry where parts have been formed by various processes, e.g. casting, forging and welded structures, as in these components, anisotropy might be another phenomenon which arises. How to handle this is also of major importance.

Clearly one can see that the phenomenon of dwell time crack growth gives rise to many problems which are yet to be solved. The modelling approach presented in this dissertation has been shown to be able to handle some of them, while more research is needed to deal with the remaining ones. 



\section{References}

[1] M Durand-Charre. The microstructure of superalloys. Gordon and Breach Science Publishers, 1997.

[2] http://www.turbokraft.se.

[3] C.T. Sims, N.S. Stoloff, W.C. Hagel. Superalloys II. Wiley-Interscience, 1987.

[4] J.R. David, editor. Heat-Resistant Materials. ASM International, 1999.

[5] R.C. Reed. The Superalloys - Fundamentals and Applications. Cambridge University Press, 2006.

[6] Haynes International Inc. http://www.haynesintl.com/.

[7] Special Metals Corp. http://http://www. specialmetals.com/.

[8] J.C. Williams, E.A. Starke Jr. Progress in structural materials for aerospace systems1. Acta Materialia, 51(19):5775-5799, 2003.

[9] R. Eriksson. Thermal Barrier Coatings Durability Assessment and Life Prediction. Ph.D. thesis, Linköping university, ISBN 978-91-7519-569-8, 2013.

[10] D.F. Socie, G.B. Marquis. Multiaxial fatigue. Society of Automotive Engineers, Inc., 2000.

[11] R.W. Herztberg. Deformation and Fracture Mechanics of Engineering Materials. John Wiley \& Sons, Inc, 1996.

[12] P.C. Paris, M.P. Gomez, W.E. Anderson. A rotational analytic theory of fatigue. The Trend in Engineering, 13:9-14, 1961.

[13] P.C. Paris, F. Erdogan. A critical analysis of crack propagation laws. Journal of Basic Engineering, 85(4):528-534, 1963.

[14] NASGRO manual 7.0, SwRI.

[15] J.C. Newman Jr. A crack opening stress equation for fatigue crack growth. International Journal of Fracture, 24:R131-R135, 1984. 
[16] T.L. Anderson. Fracture Mechanics - Fundamentals and Application. CRC Press, third edition, 2005.

[17] M. Kuna. Finite Elements in Fracture Mechanics Theory-Numerics-Applications. Springer, 2013.

[18] D. Bika, J.A. Pfaendtner, M. Menyhard, C.J. McMahon Jr. Sulfur-induced dynamic embrittlement in a low-alloy steel. Acta Metallurgica et Materialia, 43(5):1895-1908, 1995.

[19] J.M. Larsen, T. Nicholas. Load sequence crack growth transients in a superalloy at elevated temperature. Fracture Mechanics: Fourteenth Symposium - Volume II: Testing and Applications, ASTM STP 791, pp. II-536-II-552, 1983.

[20] E. Andrieu, R. Molins, H. Ghonem, A. Pineau. Intergranular crack tip oxidation mechanism in a nickel-based superalloy. Materials Science and Engineering: A, 154(1):21-28, 1992.

[21] H. Ghonem, T. Nicholas, A. Pineau. Elevated temperature fatigue crack growth in alloy 718-part II: Effects of environmental and material variables. Fatigue $\mathcal{E}$ Fracture of Engineering Materials E Structures, 16(6):577-590, 1993.

[22] J.A. Pfaendtner, C.J. McMahon Jr. Oxygen-induced intergranular cracking of a Ni-base alloy at elevated temperatures - an example of dynamic embrittlement. Acta Materialia, 49(16):3369-3377, 2001.

[23] F.V. Antunes, J.M. Ferreira, C.M. Branco, J. Byrne. Influence of stress state on high temperature fatigue crack growth in Inconel 718. Fatigue E Fracture of Engineering Materials E Structures, 24(2):127-135, 2001.

[24] X.B. Liu, L.Z. Ma, K.M. Chang, E. Barbero. Fatigue crack propagation of Ni-based superalloys. Acta Metallurgica Sinica, 18(1):55-64, 2005.

[25] D. Gustafsson, J.J. Moverare, S. Johansson, M. Hörnqvist, K. Simonsson, S. Sjöström, B. Sharifimajda. Fatigue crack growth behaviour of Inconel 718 with high temperature hold times. Procedia Engineering, 2(1):1095-1104, 2010. Fatigue 2010.

[26] T. Weerasooriya. Effect of frequency on fatigue crack growth rate of Inconel 718 at high temperature. Technical report, Air Force Wright Aeronautical Laboratories Report, AFWAL-TR-87-4038, Wright-Patterson Air Force Base, OH, 1987.

[27] M. Khobaib, N.E. Ashbaugh, G.A. Hartman, T. Weerasooriya, D.C. Maxwell, R.C. Goodman. Research on mechanical properties for engine life prediciton. Technical report, Air Force Wright Aeronautical Laboratories Report, AFWALTR-88-4062, Wright-Patterson Air Force Base, OH, 1988.

[28] R.P. Skelton, J.I. Bucklow. Cyclic oxidation and crack growth during high strain fatigue of low alloy steel. Metal Science, 12(2):64-70, 1978. 
[29] J. Gayda, T.P. Gabb, R.V. Miner. Fatigue crack propagation of nickel-base superalloys at $650^{\circ} \mathrm{C}$. In Low Cycle fatigue, ASTM STP 942, pp. 293-309, 1988.

[30] K.-M. Chang, M.F. Henry, M.G. Benz. Metallurgical control of fatigue crack propagation in superalloys. Journal of Metals, 42(12):29-35, 1990.

[31] R. Molins, G. Hochstetter, J.C. Chassaigne, E. Andrieu. Oxidation effects on the fatigue crack growth behaviour of alloy 718 at high temperature. Acta Materialia, 45(2):663-674, 1997.

[32] U. Krupp. Dynamic embrittlement - time-dependent quasi-brittle intergranular fracture at high temperatures. International Materials Reviews, 50(2):83-97, 2005.

[33] D.A. Woodford. Gas phase embrittlement and time dependent cracking of nickel based superalloys. Energy Materials: Materials Science and Engineering for Energy Systems, 1(1):59-79, 2006.

[34] A. Pineau, S.D. Antolovich. High temperature fatigue of nickel-base superalloys a review with special emphasis on deformation modes and oxidation. Engineering Failure Analysis, 16(8):2668-2697, 2009.

[35] A. Saxena. A model for predicting the environmental enhanced fatigue crack growth behavior at high temperature. Thermal and Environmetal Effects in FatigueResearch Design Interface-PVP-71, ASME, pp. 171-184, 1984.

[36] T. Nicholas, T. Weerasooriya, N.E. Ashbaugh. A model for creep/fatigue interactions in alloy 718. Fracture Mechanics: Sixteenth Symposium, ASTM STP 868, pp. 167-180, 1985.

[37] T. Nicholas, T. Weerasooriya. Hold-time effects in elevated temperature fatigue crack propagation. Fracture Mechanics: Seventeenth Volume, ASTM STP 905, pp. 155-168, 1986.

[38] H. Ghonem, D. Zheng. Depth of intergranular oxygen diffusion during environment-dependent fatigue crack growth in alloy 718. Materials Science and Engineering: A, A150(2):151-160, 1992.

[39] D. Zheng, H. Ghonem. Oxidation-assisted fatigue crack growth behavior in alloy 718-part II. applications. Fatigue E Fracture of Engineering Materials E Structures, 14(7):761-768, 1991.

[40] F. Gallerneau, S. Kruch, P. Kanouté. A new modelling of crack propagation with fatigue-creep-oxidation interaction under non isothermal loading. In Symposium on Ageing Mechanisms and Control: Part B Monitoring and Management of Gas Turbine Fleets for Extended Life and Reduced Costs, Manchester UK, 8-11 October, 2001. 
[41] S. Kruch, P. Prigent, J.L. Chaboche. A fracture mechanics based fatigue-creepenvironment crack growth model for high temperature. International Journal of Pressure Vessels and Piping, 59:141-148, 1994.

[42] J.A. Ruiz-Sabariego, S. Pommier. Oxidation assisted fatigue crack growth under complex non-isothermal loading conditions in a nickel base superalloy. International Journal of Fatigue, 31(11-12):1724 - 1732, 2009. Fatigue Damage of Structural Materials VII.

[43] L.G. Zhao, J. Tong, M.C. Hardy. Prediction of crack growth in a nickel-based superalloy under fatigue-oxidation conditions. Engineering Fracture Mechanics, 77(6):925-38, 2010.

[44] J.L. Evans and A. Saxena. Elevated temperature fatigue crack growth rate model for Ni-base superalloys. International Journal of Fracture, 185(1-2):209-216, 2014.

[45] A. Saxena, K. Findley. Dwell-time fatigue crack growth in Ni-base superalloys. Technical report, AFRL-ML-TR-2007-4117, Air Force Research Laboratory, Wright-Patterson Air Force Base, OH, 2003.

[46] K.O. Findley, J.L. Evans, A. Saxena. A critical assessment of fatigue crack nucleation and growth models for $\mathrm{Ni}$ - and $\mathrm{Ni}$, Fe-based superalloys. International Materials Reviews, 56(1):49-71, 2011.

[47] J.L. Bouvard, F. Gallerneau, P. Paulmier, J.L. Chaboche. A phenomenological model to predict the crack growth in single crystal superalloys at high temperature. International Journal of Fatigue, 38:130-143, 2012.

[48] J.L. Evans, A. Saxena. Elevated temperature crack growth rate model for Ni-base superalloys. Proc. 12th Int. Conf. on Fracture, Ottawa Canada, 2009.

[49] K.S. Chan, M.P. Enright, J.P. Moody, B. Hocking, S.H.K. Fitch. Life prediciton for turbopropulsion systems under dwell fatigue conditions. In Proceedings of ASME Turbo Expo 2012, GT2012-69742, June 11-15, 2012 Copenhagen, Denmark, 2012.

[50] C.J. McMahon Jr. Comments on "identification of SAGBO-induced damage zone ahead of crack tip to characterize sustained loading crack growth in alloy 783". Scripta Materialia, 54(2):305-307, 2006.

[51] S.Y. Yu, H.Y. Li, M.C. Hardy, S.A. McDonald, P. Bowen. Mechanisms of dwell fatigue crack growth in an advanced nickel disc alloy RR1000. 2nd European Symposium on Superalloys and Their Applications, EUROSUPERALLOYS 2014, 14, 2014.

[52] U. Krupp, W.M. Kane, C. Laird, C.J. McMahon. Brittle intergranular fracture of a Ni-base superalloy at high temperatures by dynamic embrittlement. Materials Science and Engineering: A, 387-389(0):409-413, 2004. 13th International Conference on the Strength of Materials. 
[53] J.J. Moverare, D. Gustafsson. Hold-time effect on the thermo-mechanical fatigue crack growth behaviour of Inconel 718. Materials Science and Engineering: A, 528(29-30):8660-8670, 2011.

[54] A. Diboine, A. Pineau. Creep crack initiation and growth in Inconel 718 alloy at $650^{\circ} \mathrm{C}$. Fatigue \& Fracture of Engineering Materials \& Structures, 10(2):141-151, 1987.

[55] J. Saarimäki, J. Moverare, R. Eriksson, S. Johansson. Influence of overloads on dwell time fatigue crack growth in Inconel 718. Materials Science and Engineering: A, 612:398-405, 2014.

[56] D. Gustafsson. High temperature fatigue crack propagation behaviour of Inconel 718. Ph.D. thesis, Linköping University, ISBN 978-91-7519-750-0, 2013.

[57] J.C. Newman Jr., C.A. Bigelow, K.N. Shivakumar. Three-dimensional elasticplastic finite element analyses of constraint variations in cracked bodies. Engineering Fracture Mechanics, 46:1-13, 1993. 

Part II

Appended papers 



\section{Appended Papers}

The articles associated with this thesis have been removed for copyright reasons. For more details about these see:

http://urn.kb.se/resolve?urn=urn:nbn:se:liu:diva-121012 